PET tracers for somatostatin receptor imaging of neuroendocrine tumors current status and review of the literature

Johnbeck, Camilla Bardram; Knigge, Ulrich; Kjær, Andreas

Published in:

Future Oncology

DOI:

10.2217/fon.14.139

Publication date:

2014

Document version

Publisher's PDF, also known as Version of record

Document license:

CC BY-NC

Citation for published version (APA):

Johnbeck, C. B., Knigge, U., \& Kjær, A. (2014). PET tracers for somatostatin receptor imaging of

neuroendocrine tumors: current status and review of the literature. Future Oncology, 10(14), 2259-2277.

https://doi.org/10.2217/fon.14.139 


\section{PET tracers for somatostatin receptor imaging of neuroendocrine tumors: current status and review of the literature}


imaging, as well as peptide receptor radionuclide therapy (PRRT) by radiolabeled targeting of these receptors. Somatostatin receptors are G-protein-coupled membrane glycoproteins, and so far, five subtypes of human somatostatin receptors have been identified: sst $1-$ sst 5 [12]. GEP NETs are found to express somatostatin receptors in $80-100 \%$ of cases, although insulinomas have a lower prevalence (50-70\%) $[13,14]$. Most abundant is sst2 [15], followed by equal amounts of sst1 and sst5, lower amounts of sst3 and hardly any sst4 [14-16]. In total, 70-90\% of NETs express sst 2 [17].

The first available somatostatin analog was octreotide, a synthetic octapeptide that exhibited more selective high-affinity binding for sst 2 and sst 5 and, to a lesser degree, sst3 [18]. Altering small parts of the synthetic peptides readily changes the binding profile to different receptors. Lanreotide and pasireotide are newer long-acting somatostatin analogs that were developed in order to refine clinical effects and gain a broader affinity profile [10]. Furthermore, in the development of tracers for the molecular imaging of NETs, synthetic somatostatin analogs have played a crucial role.

\section{Somatostatin receptor imaging}

In 1989, the first somatostatin receptor scintigraphies were performed using ${ }^{123} \mathrm{I}_{-} \mathrm{Tyr}^{3}$-octreotide [19]. One-thousand patients were scanned using $\gamma$-camera-based scintigraphy, and a sensitivity of $80-95 \%$ was found for carcinoids and endocrine pancreatic tumors [20].

For many years, the radiopharmaceutical of first choice for the visualization of NETs has been ${ }^{111} \mathrm{In}$-pentreotide, and in the USA, this remains the case. ${ }^{111}$ In radioisotopes emits $\gamma$-radiation and thus imaging is obtained by either planar or tomographical $\gamma$-cameras, such as single photon emission computed tomography (SPECT). PET-based radioisotopes such as ${ }^{18} \mathrm{~F}$, ${ }^{68} \mathrm{Ga}$ and ${ }^{64} \mathrm{Cu}$ emit positrons. When the positrons annihilate with an electron, two photons are emitted in opposite directions, and these are detected by the PET scanner.

Combinations with new chelators and PET isotopes have made somatostatin receptor imaging even more sensitive. In general, the sensitivity and resolution is better for PET scanning than for SPECT. Moreover, the quantitative nature of PET makes it possible to quantify the amount of tracer uptake expressed as standardized uptake values (SUVs). The SUVs are very useful in the planning of PRRT and may contain prognostic information [21].

Several studies have determined that PET tracers possess major advantages compared with the $\gamma$-emitting tracers, both in terms of detection rates and clinical impact [22-27]. Furthermore, the PET examination takes only a few hours instead of 2-3 days and the costs are also reduced because supplementary MRI or computed tomography (CT) scanning is needed less often [28].

In the European consensus guidelines of ENETS from 2012, SPECT/CT scanning using ${ }^{111}$ In-DTPA-octreotide (DTPA-OC) is an important part of the diagnostic work-up of patients with NETs. However, a change towards the PET-based tracers is preferred whenever possible [29-32], especially for patients with colonic NETs, insulinomas and multiple endocrine neoplasia syndromes $[33,34]$.

\section{Somatostatin receptor PET tracers}

Labeling peptides moved a step forward with the introduction of 1,4,7,10-tetraazacyclodecane1,4,7,10-tetraacetic acid (DOTA), a universal chelator capable of forming stable complexes with radiotracers of the metal group, such as ${ }^{111} \mathrm{In},{ }^{67} \mathrm{Ga},{ }^{68} \mathrm{Ga},{ }^{64} \mathrm{Cu},{ }^{90} \mathrm{Y}$ and ${ }^{177} \mathrm{Lu}$ [29]. Peptides labeled with ${ }^{90} \mathrm{Y}$ and ${ }^{177} \mathrm{Lu}$ are used for radionuclide therapy, while most somatostatin receptor imaging tracers use ${ }^{68} \mathrm{Ga}$ as the radioisotope. This isotope has the advantage of being produced from a generator, so it is also available in departments without a cyclotron.

The receptor affinity, radiation type, duration and positron range of the emissions are all of crucial importance for the efficacy of a PET tracer, both in imaging and radionuclide therapy. Even small modifications in the amino acid sequences, as well as conjugation to a chelator and the choice of isotope, may lead to changes in the affinity towards different receptors $[22,35]$. A change from antagonistic to agonistic hehavior has even been described after conjugation to the DOTA chelator [36]. Somatostatin receptor internalization appears to be inducible only by somatostatin agonists and not antagonists $[37,38]$. Internalization of the receptor-ligand complex has been considered to be necessary for imaging and radionuclide therapy; however, preclinical studies have shown that antagonists bind to more receptor sites than agonists and dissociate more slowly, leading to a strong and possibly longacting radiation signal $[39,40]$. A single clinical study has compared ${ }^{111}$ In-DTPA-octreotide and 
an antagonist tracer ${ }^{111} \mathrm{In}-\mathrm{DOTA}-\mathrm{pNO}_{2}$-Phec(DCys-Tyr-DTrp-Lys-Thr-Cys) DTyrNH ${ }_{2}$ (BASS) in five NET patients. The antagonist tracer found more lesions and showed up to four-times higher tumor uptake of the tracer [41]. In spite of this, the agonist somatostatin analogs are so far the only ones that are used in clinical routine.

The principle of combining radioisotopes, chelators and somatostatin analogs is shown for the most commonly used tracers in Figure 1.

The most frequently used modifications of octreotide are $\mathrm{Tyr}^{3}$-octreotide, $\mathrm{Tyr}^{3}$ octreotate and $1-\mathrm{Nal}^{3}$-octreotide. When combined with the DOTA chelator and ${ }^{68} \mathrm{Ga}$, they are called ${ }^{68} \mathrm{Ga}$-DOTA-Tyr3-octreotide $\left({ }^{68} \mathrm{Ga}\right.$-DOTATOC), ${ }^{68} \mathrm{Ga}$-DOTA-Tyr3octreotate $\left({ }^{68} \mathrm{Ga}\right.$-DOTATATE) and ${ }^{68} \mathrm{Ga}$-DOTA1-Nal3-octreotide ( ${ }^{68} \mathrm{Ga}$-DOTANOC). Furthermore, combinations using somatostatin analogs coupled to ${ }^{64} \mathrm{Cu}$ has been reported by a few centers $[42,43]$.

\section{Somatostatin receptor tracer affinity}

The binding to the relevant somatostatin receptors is the most crucial factor for the efficacy of imaging with somatostatin receptor tracers.
The results of in vitro binding studies of the most used somatostatin receptor PET tracers are shown in Table 1.

The highest affinity was found for Ga-DOTATATE towards the most abundant receptor sst2. Reubi et al. determined the binding affinity of Ga-DOTATATE towards sst2 to be approximately tenfold higher than that of both Ga-DOTANOC and Ga-DOTATOC [35]. Ga-DOTATATE (and In-DTPA-octreotide) only binds to sst2, while Ga-DOTATOC, Ga-DOTAOC and Ga-DOTANOC also binds to sst5. Ga-DOTANOC had a tenfold higher affinity than Ga-DOTATOC and additional binding capacity towards sst3 [35,44]. The somatostatin analog lanreotide has been claimed to be a universal somatostatin receptor agonist, but affinity studies of lanreotide coupled to the DOTA chelator only show relevant affinity for sst 2 and sst 5 [35]. The affinity measurements were made in vitro in cells transfected with the five types of somatostatin receptors. Differences may therefore occur in vivo.

\section{- Influence of the chelator \& radionuclide}

So far, it has mainly been ${ }^{68} \mathrm{Ga}$ that has been used as the radioisotope in somatostatin receptor PET

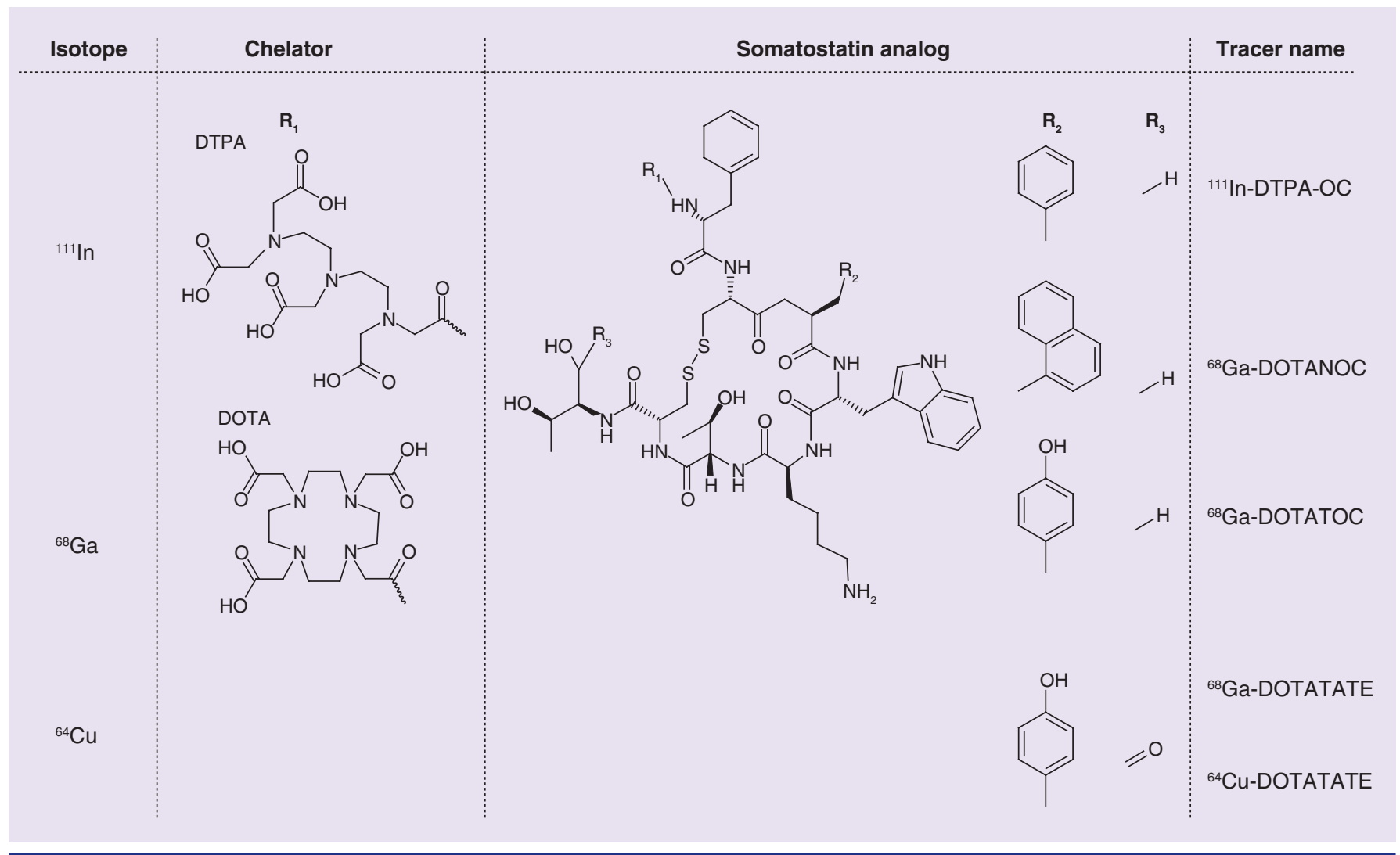

Figure 1. The chemical structure of somatostatin receptor tracers: isotope plus chelator plus somatostatin analog. 


\begin{tabular}{|c|c|c|c|c|c|c|}
\hline Somatostatin analog & Name & sst1 & sst2 & sst3 & sst4 & sst5 \\
\hline Ga-DOTA-Tyr ${ }^{3}$-octreotate & Ga-DOTATATE & $>10,000$ & $0.2 \pm 0.04$ & $>1000$ & $300 \pm 140$ & $377 \pm 18$ \\
\hline Ga-DOTA-Tyr ${ }^{3}$-octreotide & Ga-DOTATOC & $>10,000$ & $2.5 \pm 0.5$ & $613 \pm 140$ & $>1000$ & $73 \pm 21$ \\
\hline Ga-DOTA-octreotide & Ga-DOTAOC & $>10,000$ & $7.3 \pm 1.9$ & $120 \pm 45$ & $>1000$ & $60 \pm 14$ \\
\hline Ga-DOTA-I-Nal³-octreotide & Ga-DOTANOC & $>10,000$ & $1.9 \pm 0.4$ & $40 \pm 5.8$ & $260 \pm 74$ & $7.2 \pm 1.6$ \\
\hline DOTA-lanreotide & DOTALAN & $>10,000$ & $26 \pm 3.4$ & $771 \pm 229$ & $>10,000$ & $73 \pm 12$ \\
\hline In-DTPA-octreotide & In-DTPA-OC & $>10,000$ & $22 \pm 3.6$ & $182 \pm 13$ & $>1000$ & $237 \pm 52$ \\
\hline
\end{tabular}

tracers. In contrast to the radioisotopes ${ }^{18} \mathrm{~F}$ and ${ }^{64} \mathrm{Cu}$, which are cyclotron produced, ${ }^{68} \mathrm{Ga}$ has the advantage of being produced by a generator, making it more easily available. A rationale for using ${ }^{64} \mathrm{Cu}$ instead of ${ }^{68} \mathrm{Ga}$, however, is its longer half-life (12.7 h vs $68 \mathrm{~min}$.) and lower positron energy and thus short positron range (maximal energy of positrons $\left[\mathrm{E}_{\max , \beta}^{+}\right] 0.58 \mathrm{MeV}$ and maximal positron range $\left[\mathrm{R}_{\max }\right]<3 \mathrm{~mm}$ vs $\mathrm{E}_{\text {max }, \beta}{ }^{+} 1.90 \mathrm{MeV}$ and $\mathrm{R}_{\max } 9 \mathrm{~mm}$ ), which might give it some advantages, even though the higher percentage of $\beta$-radiation may favor ${ }^{68} \mathrm{Ga}$ as a PET tracer (88 vs $19 \%$ ).

Anderson et al. used the triethylenetetramine chelator to combine octreotide and ${ }^{64} \mathrm{Cu}$. Compared with ${ }^{111}$ In-DTPA-OC, more lesions were found in two out of eight patients using ${ }^{64} \mathrm{Cu}$-triethylenetetramine-octreotide [42].

Pfeifer et al. used the DOTA chelator to chelate $\mathrm{Tyr}^{3}$-octreotate and ${ }^{64} \mathrm{Cu}$. A high and quite stable maximum SUV (SUV ${ }_{\max }$ ) for lesions on both early (1 h) and delayed (3 h) images suggested a high rate of tracer internalization and a low dissociation rate of ${ }^{64} \mathrm{Cu}$-DOTATATE from somatostatin receptors during this time interval. SUV stability illustrated sufficient in vivo stability of the tracer for imaging purposes, even though some ${ }^{64} \mathrm{Cu}$ dissociation was seen in the liver. Compared with ${ }^{111}$ In-DTPA-OC SPECT, additional lesions were found in six out of 14 patients (43\%) [43]. Most notably, imaging was attained using a dose that gave only half the radiation burden compared with ${ }^{111}$ In-DTPA-OC.

From a physical point of view, ${ }^{18} \mathrm{~F}$ constitutes the ideal radionuclide for PET, due to its high amount of positron emission (97\%), low positron energy and short positron range $\left(\mathrm{E}_{\max , \beta}{ }^{+} 0.63 \mathrm{MeV}\right.$ and $\mathrm{R}_{\max }<3 \mathrm{~mm}$ ), which is comparable with that of ${ }^{64} \mathrm{Cu}$. Meisetschläger et al. tested the somatostatin receptor tracer Gluc-Lys $\left({ }^{18} \mathrm{~F}\right.$-fluoropropionyl)Tyr3-octreotate $\left.\left[{ }^{18} \mathrm{~F}-\mathrm{FP}\right]-\mathrm{TOCA}\right)$ in a direct comparison to ${ }^{111} \mathrm{In}-\mathrm{DTPA}-\mathrm{OC}$ in 16 NET patients.
Gluc-Lys $\left({ }^{18} \mathrm{~F}-\mathrm{FP}\right)$-TOCA detected more than twice as many lesions and was rapidly taken up in the tumors, reaching $80 \%$ of the maximum tumor-to-background ratio at $16 \pm 6.9 \mathrm{~min}$ after injection. The tumor-to-background ratio in the liver was $4.2 \pm 2.0$ at $60 \mathrm{~min}$ and thus comparable with ${ }^{68} \mathrm{Ga}$-DOTATOC. The main drawback of Gluc-Lys $\left({ }^{18} \mathrm{~F}-\mathrm{FP}\right)-\mathrm{TOCA}$ is its time-consuming multistep radiosynthesis and its limited overall yield [45].

Whether the differences in affinity among the tracers are important for imaging NETs also depends on the amount and distribution of somatostatin receptor in the normal tissue from which the tumors have to be differentiated.

\section{- Physiological uptake of somatostatin receptor PET tracers}

It is well known that SUVs are highly dependent on scanner resolution and image reconstruction techniques and may differ significantly between departments [46]. Absolute values of uptake in normal tissues of the different tracers are therefore difficult to compare unless performed by the same department, and no such data exist in the literature. Physiological uptakes for each of the most commonly used tracers have, however, been examined separately [47-49].

The ratios between tumor and normal tissue are of major importance in order to achieve optimal imaging. These ratios have been evaluated for ${ }^{68} \mathrm{Ga}$-DOTATOC and ${ }^{68} \mathrm{Ga}$-DOTANOC $[47,48]$. The scanning details and results are shown in Table 2.

Rather high physiological uptake is seen in the spleen and kidneys for all three tracers and in the adrenal and pituitary gland as well, especially with ${ }^{68} \mathrm{Ga}$-DOTATATE and ${ }^{68} \mathrm{Ga}$-DOTATOC. Of special importance is the physiological uptake in the liver, bone and normal pancreas due to the predominant localizations of NETs and metastases to 
these organs. The uptake ratio between NET and normal tissue in the liver is approximately 3 for both ${ }^{68} \mathrm{Ga}$-DOTANOC and ${ }^{68} \mathrm{Ga}$-DOTATOC, and even higher ( 10) in bones. Thus, good conditions were found for the imaging of NETs in these organs. The discrimination between NET and normal pancreatic tissue, especially in the processus uncinatus, has been much debated, and definitions of absolute SUV cut-off values in order to define tumor against normal tissue have been suggested by some $[47,48]$, but not found to be practicable by others [50]. In 76 out of 103 scans, Krausz et al. found 97 sites of ${ }^{68} \mathrm{Ga}$-DOTANOC uptake in the pancreas [50]. A total of 38 sites were judged to be due to physiological uptake, and 31 of these were in the processus uncinatus. Thus, tracer uptake in the processus uncinatus of the pancreas must be interpreted with caution. Cutoff values would be the perfect tool for diagnostic imaging, but they can seldom be defined and are not used in the clinical routine.

\section{Performance of the somatostatin receptor PET tracers}

A comparison of the sensitivity, specificity and usefulness of the different tracers in the

\section{Table 2. Uptake of most used somatostatin receptor PET tracers in normal tissues and neuroendocrine tumors.}

\begin{tabular}{|c|c|c|c|}
\hline Parameter & ${ }^{68} \mathrm{Ga}-\mathrm{DOTANOC}[48]$ & ${ }^{68} \mathrm{Ga}$-DOTATATE [49] & ${ }^{68} \mathrm{Ga}$-DOTATOC [47] \\
\hline Patients (n) & 89 & 250 & 249 \\
\hline Dose and preparation & $\begin{array}{l}80-160 \text { MBq iv., } 1.5 \text { I water equivalent } \\
\text { contrast (gastrografin) orally }\end{array}$ & $\begin{array}{l}120-220 \mathrm{MBq} \text { iv. }+20 \mathrm{mg} \text { furosemid, } \\
1.5 \text { I water orally }\end{array}$ & $\begin{array}{l}\text { 68-220 MBq iv., full-dose, } \\
\text { contrast-enhanced CT on most }\end{array}$ \\
\hline Scan protocol & Scan 60-100 min Pl, 2-3 min/bed & Scan 60-80 min PI, 3 min/bed & $51-148 \mathrm{~min} \mathrm{Pl}, 2 \mathrm{~min} / \mathrm{bed}$ \\
\hline PET/CT used & $\begin{array}{l}\text { Biograph }^{\text {TM }} \text { Duo (Siemens Medical } \\
\text { Solutions, Germany) }\end{array}$ & $\begin{array}{l}\text { Biograph } 64 \text { TruePoint }^{\mathrm{TM}} \text { PET/CT } \\
\text { scanner, 3D mode (Siemens Medical } \\
\text { Solutions) }\end{array}$ & $\begin{array}{l}\text { Discovery }{ }^{\mathrm{TM}} \text { 690, 3D mode (GE } \\
\text { Healthcare, WI, USA) }\end{array}$ \\
\hline Uptake & ${ }^{68} \mathrm{Ga}$-DOTANOC & ${ }^{68} \mathrm{Ga}$-DOTATATE ${ }^{\dagger}$ & ${ }^{68} \mathrm{Ga}-\mathrm{DOTATOC}+$ \\
\hline \multicolumn{4}{|l|}{ Liver: } \\
\hline - Normal & $6.9 \pm 2.0$ & $6.5 \pm 2.2$ & $12.5 \pm 4.0$ \\
\hline - Metastases & $19.6 \pm 13.4$ & NR & $29.8 \pm 16.5$ \\
\hline - Ratio & $3.4 \pm 2.3$ & NR & $2.8 \pm 1.6(4.7$ at $90 \mathrm{~min})$ \\
\hline \multicolumn{4}{|l|}{ Bone: } \\
\hline - Normal & $0.8 \pm 0.3$ & $1.0 \pm 0.3$ & $1.9 \pm 0.8$ \\
\hline - Metastases & $9.5 \pm 6.0$ & NR & $19.8 \pm 18.8$ \\
\hline - Ratio & $11.3 \pm 8.9$ & NR & $10.5 \pm 14.2$ \\
\hline \multicolumn{4}{|l|}{ Pancreas: } \\
\hline - Processus uncinatus & $5.8 \pm 2.0$ & $6.5 \pm 2.2$ & $10.5 \pm 4.1$ \\
\hline - Primary tumor & $20.8 \pm 10.8$ & NR & $33.6 \pm 14.1$ \\
\hline - Ratio & NR & NR & $5.2 \pm 2.8$ \\
\hline \multicolumn{4}{|l|}{ Muscle: } \\
\hline - Normal & $1.0 \pm 0.3$ & NR & $2.3 \pm 1.0$ \\
\hline \multicolumn{4}{|l|}{ Lymph node: } \\
\hline - Metastases & $12.5 \pm 10.0$ & NR & NR \\
\hline \multicolumn{4}{|l|}{ Spleen: } \\
\hline - Normal & $22 \pm 10.0$ & $18.9 \pm 6.6$ & $32.6 \pm 11.8$ \\
\hline \multicolumn{4}{|l|}{ GI: } \\
\hline - Normal & $2.6 \pm 1.0$ & NR & $4.7 \pm 1.9$ \\
\hline \multicolumn{4}{|l|}{ Pituitary gland: } \\
\hline - Normal & $2.6 \pm 1.3$ & $11 \pm 4.5$ & $8.0 \pm 3.5$ \\
\hline \multicolumn{4}{|l|}{ Adrenal glands: } \\
\hline - Normal & $6.0 \pm 2.5$ & $14 \pm 5.6$ & $16.3 \pm 5.8$ \\
\hline \multicolumn{4}{|l|}{ Kidneys: } \\
\hline - Normal & $12.9 \pm 3.8$ & $14.2 \pm 3.6$ & $20.4 \pm 7.7$ \\
\hline
\end{tabular}


diagnosis of NETs is difficult to extract from the existing literature. Direct head-to-head comparison of the tracers in the same patients are sparse. Most studies have been performed with one tracer at a time and in heterogeneous patient groups, including many different NET types and localizations.

The approach to defining the gold standard for detecting existing disease - the crucial factor for determining sensitivity and specificity - also varies between studies. Different approaches have been used. The most common is the patient-based approach, testing whether the tracer detects disease in the patient or not. This is quite an approximate estimate and may be clinically insufficient since the presence of metastases in different regions is very important for the choice of treatment. Some have tried to compensate for this by dividing detected lesions into clinically relevant regions in order to assess the clinical impact of additional findings. Others have looked into every single lesion in order to determine the differences between two tracers or modalities. The approach with multiple lesions in every patient leaves the problem of verifying them all. It is not ethically reasonable to achieve histological confirmation of every lesion, so CT and/or MRI have mostly been used in order to confirm or exclude the positive PET findings. Buchmann et al. used CT and MRI only for positive verifications of lesions detected by PET, since the sensitivity might be higher for the PET modality than CT or MRI [23]. Many studies use a follow-up period of a certain length in order to verify the presence or absence of disease. This may be the best approach to reaching a gold standard; however, in slow-growing tumors, the followup period needs to be quite long. An important factor is the heterogeneity of tumors is their varying receptor profiles. For instance, there will be a large difference in the sensitivity of somatostatin receptor PET tracers used to detect insulinomas that are known to express lower amounts of sst2 compared with small intestinal NETs, which virtually all express sst 2 [51].

In Tables 3-5, the diagnostic performance of the three most commonly used somatostatin receptor PET tracers are listed.

\section{- Head-to-head comparison of the somatostatin receptor PET tracers}

In only five studies have direct comparisons of two PET tracers using the same patient population been performed [59,60,67-69]. Poeppel et al. examined 40 NET patients with both
${ }^{68} \mathrm{Ga}$-DOTATOC and ${ }^{68} \mathrm{Ga}$-DOTATATE [67]. Using ${ }^{68} \mathrm{Ga}$-DOTATOC, they found 262 CT-verified lesions compared with 254 found by ${ }^{68} \mathrm{Ga}$-DOTATATE. Comparing the two scans lesion to lesion, the standardized maximum uptake was higher overall with ${ }^{68} \mathrm{Ga}$-DOTATOC than ${ }^{68} \mathrm{Ga}$-DOTATATE, in addition to when the values were normalized to liver or muscle tissue. However, the tumor uptake varied considerably both within and between the patients. In addition to 18 patients with lesions displaying the highest uptake on ${ }^{68} \mathrm{Ga}$-DOTATOC, 18 patients showed a mixture of lesions with either the highest uptake on ${ }^{68} \mathrm{Ga}$-DOTATATE or ${ }^{68} \mathrm{Ga}$-DOTATOC, while lesions only showing the highest uptake on ${ }^{68} \mathrm{Ga}$-DOTATATE were found in four patients [67]. The presence of sst 5 in the group of NETs displaying higher values with ${ }^{68} \mathrm{Ga}$-DOTATOC might explain these results. When dividing all of the lesions into eight regions and counting the regions with at least one positive lesion, there was no significant difference between ${ }^{68} \mathrm{Ga}$-DOTATATE and ${ }^{68} \mathrm{Ga}$-DOTATOC, making the differences less clinically relevant.

Kabasakal et al. have compared the detection of NET lesions in a head-to-head comparison of ${ }^{68} \mathrm{Ga}$-DOTATATE and ${ }^{68} \mathrm{Ga}$-DOTANOC in 20 patients (Tables 4 \& 5) [59]. ${ }^{68} \mathrm{Ga}$-DOTATATE detected 130 lesions while ${ }^{68} \mathrm{Ga}$-DOTANOC detected 116 lesions, but this was not significantly different. Sensitivity on a patient level was calculated to be equally high at $93 \%$ in both scans, and the specificity was $100 \%$. The amount of tracer in the lesions was significantly higher in ${ }^{68} \mathrm{Ga}$-DOTATATE compared with ${ }^{68} \mathrm{Ga}$-DOTANOC $(\mathrm{p}<0.05)$ [59]. This is in concordance with the nearly ten-times higher affinity of ${ }^{68} \mathrm{Ga}$-DOTATATE towards sst 2 and emphasizes that additional affinities for sst 3 or sst 5 do not add to the performance of the tracer in this mixed NET patient population.

Wild et al. also compared ${ }^{68} \mathrm{Ga}$-DOTATATE and ${ }^{68} \mathrm{Ga}$-DOTANOC directly (Tables $4 \& 5$ ) [60]. Both of the tracers correctly identified 17 out of 18 patients with verified NETs. On a lesion-based analysis, ${ }^{68} \mathrm{Ga}$-DOTANOC performed significantly better, detecting 238 out of 248 lesions compared with 212 out of 248 . ${ }^{68} \mathrm{Ga}$-DOTANOC showed a lower uptake in normal liver compared with ${ }^{68} \mathrm{Ga}$-DOTATATE, and the additional lesions that were found were mainly due to detecting more liver lesions. ${ }^{68} \mathrm{Ga}$-DOTATATE, however, detected more bone lesions. ${ }^{68} \mathrm{Ga}$-DOTANOC found 


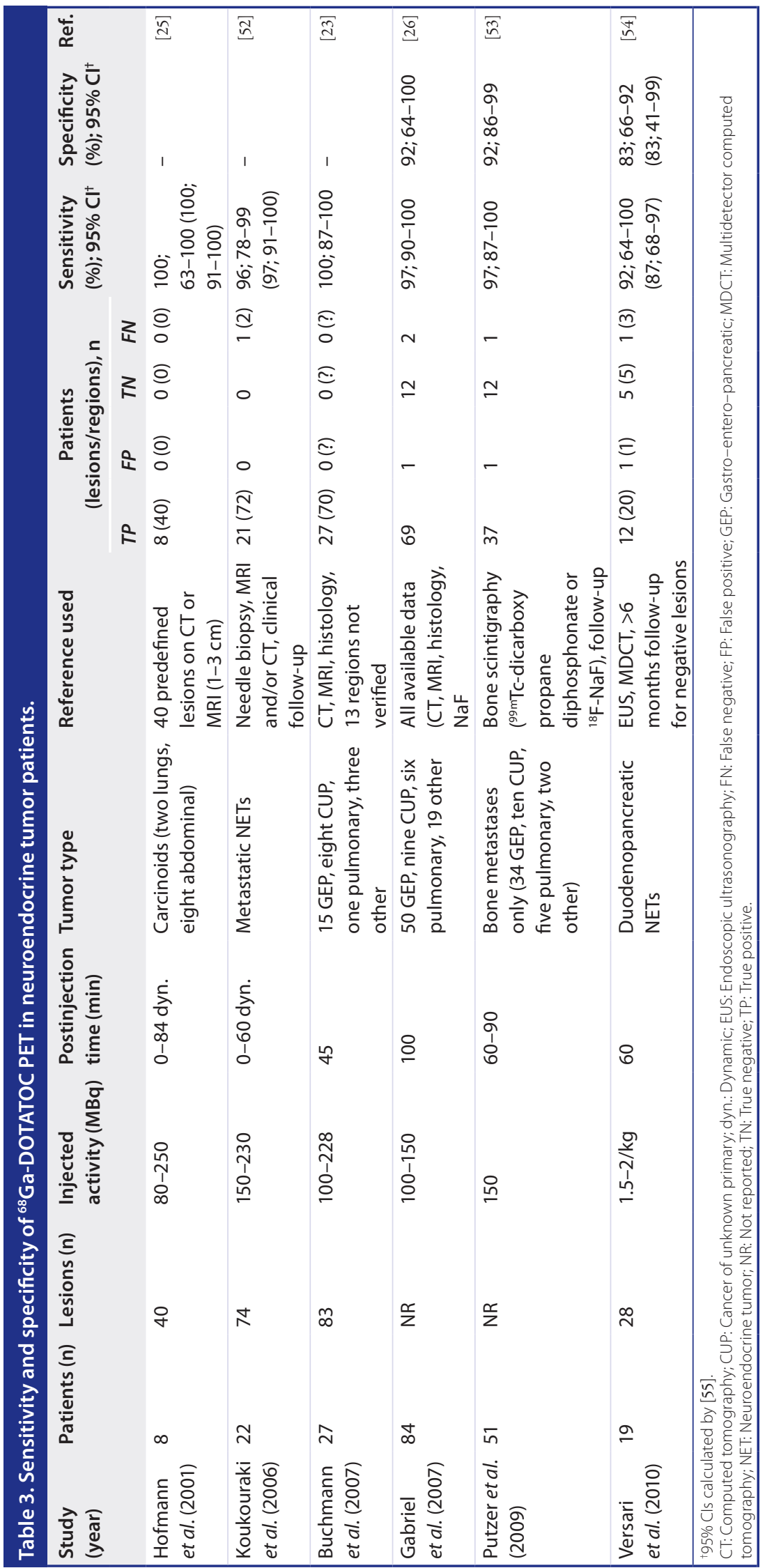




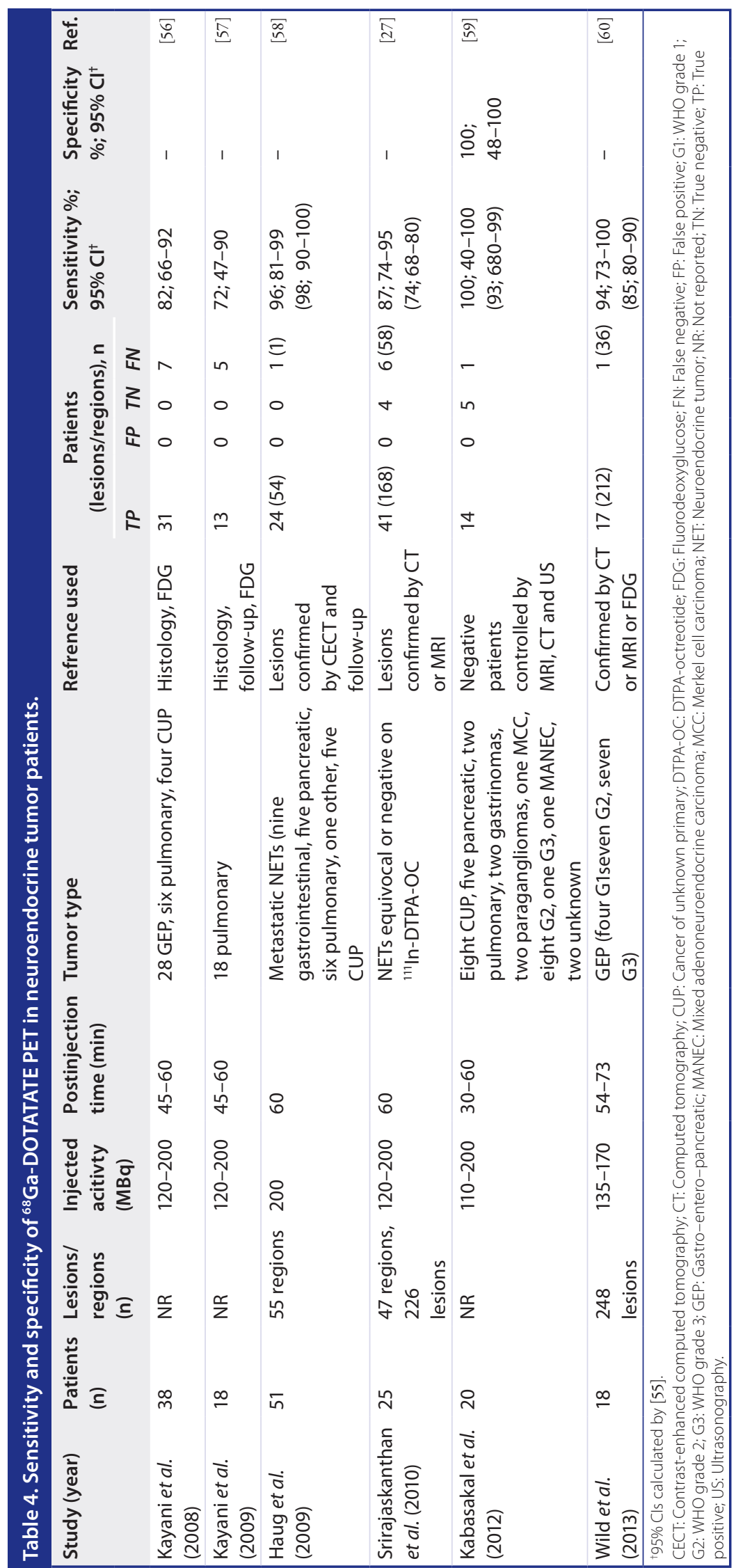

seven out of eight pancreatic NETs, whereas ${ }^{68} \mathrm{Ga}$-DOTATATE found only three [60].

In a study by Putzer $e t$ al., the new PET tracer ${ }^{68} \mathrm{Ga}$-DOTA-lanreotide (DOTALAN) was used in order to elucidate whether 38 patients who, despite clinical sign of progression but had not qualified for PRRT by ${ }^{68} \mathrm{Ga}$-DOTATOC, could benefit from PRRT using ${ }^{90}$ Y-labeled lanreotide [68]. The tumor-to-background ratios calculated from SUV ${ }_{\text {max }}$ measurements were significantly higher for ${ }^{68} \mathrm{Ga}$-DOTATOC, and ${ }^{68} \mathrm{Ga}$-DOTATOC revealed significantly more tumor sites than ${ }^{68} \mathrm{Ga}$-DOTALAN (106 vs 53). In eight of the patients who underwent both scans, the primary tumor was a thyroid tumor, and six out of eight had a higher SUV ${ }_{\text {max }}$ using ${ }^{68} \mathrm{Ga}$-DOTALAN, perhaps demonstrating thyroid NETs being more prone to PRRT when using DOTALAN [68].

${ }^{68} \mathrm{Ga}$-DOTALAN was compared with ${ }^{68} \mathrm{Ga}$-DOTATATE in a study by Demirci $e t a l$. [69]. A heterogeneous group of 11 NET patients and one meningioma patient was compared lesion by lesion. Together, the two scans revealed 67 lesions. A total of 63 lesions were found by ${ }^{68} \mathrm{Ga}$-DOTATATE, while only 23 lesions were found by ${ }^{68} \mathrm{Ga}$-DOTALAN. There was a higher amount of physiological uptake in the bone marrow with ${ }^{68} \mathrm{Ga}$-DOTALAN, and furthermore, the tumor lesions had a higher uptake of ${ }^{68} \mathrm{Ga}$-DOTATATE in general [69].

Comparison of ${ }^{64} \mathrm{Cu}$-DOTATATE and ${ }^{68} \mathrm{Ga}$-DOTATOC is currently being undertaken in our department, but results are not yet available. However, by comparing the image quality and resolution, ${ }^{64} \mathrm{Cu}$-DOTATATE seems promising (Figure 2). Greater detail is obtained with the use of ${ }^{64} \mathrm{Cu}$-DOTATATE, probably due to the difference in positron range as described earlier. The inhomogeneous uptake in the large liver metastasis seen on the ${ }^{64} \mathrm{Cu}$-DOTATATE scan might be interpreted as necrotic tissue and these details are not as clearly seen on the ${ }^{68} \mathrm{Ga}$-DOTATOC scan.

\section{- Performance of the individual somatostatin receptor PET tracers}

In 2012, Treglia et al. published a meta-analysis on the diagnostic performance of ${ }^{68} \mathrm{Ga}$-labeled PET scans in 567 cases of thoracic and GEP NETs [70]. The pooled sensitivity and specificity values of ${ }^{68} \mathrm{Ga}$-labeled somatostatin receptor PET tracers (irrespective of tracer type) for detecting GEP or thoracic NETs were 93\% (91-95\%) and 91\% 


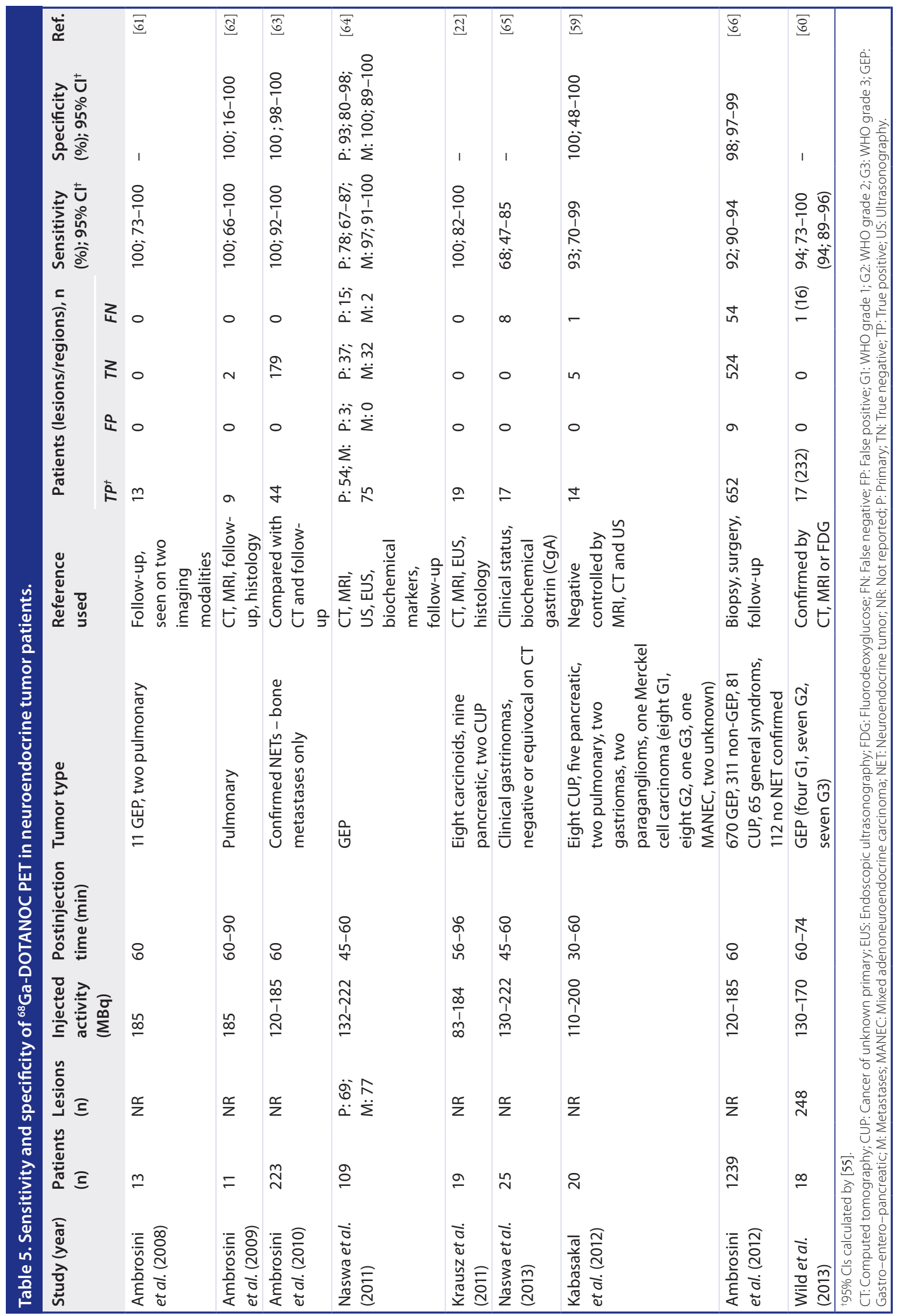


(82-97\%), respectively. Looking at the performances of the tracers individually, the sensitivity of ${ }^{68} \mathrm{Ga}$-DOTATOC (Table 3) for the patient-based studies was $92-100 \%$ and the specificity was 83-100\%. For ${ }^{68} \mathrm{Ga}$-DOTATATE (Table 4), the sensitivity seemed to be a little lower at $72-96 \%$, and the specificity was only reported in a few studies to $100 \%$. For ${ }^{68} \mathrm{Ga}$-DOTANOC (Table 5), the sensitivity ranged from 68 to $100 \%$ and the specificity from 93 to $100 \%$.

Taken together, no clear picture of the better performance of one tracer is obvious. However, there could be differences between specific NET types, as they express varying amounts of somatostatin receptor subtypes. The heterogeneity of the tumors in most of the studies can be seen from the tables. However, some studies are focused on specific tumor types and are thus more reliable for the specific type.

\section{- Somatostatin receptor PET tracers for different types of NETs \\ GEP NETs}

In 2011, Naswa et al. published results from 109 patients with GEP NETs examined with
${ }^{68} \mathrm{Ga}$-DOTANOC and with the use of all common imaging modalities, biochemichal markers and follow-up as references (Table 5) [64]. Metastases were seen in 77 patients and the sensitivity and specificity values were high for these (97 and 100\%, respectively), whereas the sensitivity was only $78 \%$ for the primary tumors, with a specificity of $93 \%$. Other smaller studies have found sensitivity values on $94-100 \%$ for GEP NETs [60,61].

${ }^{68} \mathrm{Ga}$-DOTATOC showed $100 \%$ sensitivity for the eight GEP NET patients included in a study by Hofmann et al. in 2001 [25], and 97\% sensitivity for the 50 GEP NET patients included in a study by Gabriel et al. [26]. Versari et al. found a sensitivity of $92 \%$ and a specificity of only $83 \%$ in 19 patients with duodenopancreatic NETs using ${ }^{68} \mathrm{Ga}$-DOTATOC (Table 3) [54]. These results might be explained by the previously mentioned difficult interpretations of uptake in the normal pancreatic tissue. In 25 patients with clinically defined gastrinomas with equivocal or negative findings on CT, Naswa et al. reported a sensitivity of $68 \%$ using ${ }^{68} \mathrm{Ga}$-DOTANOC [65].

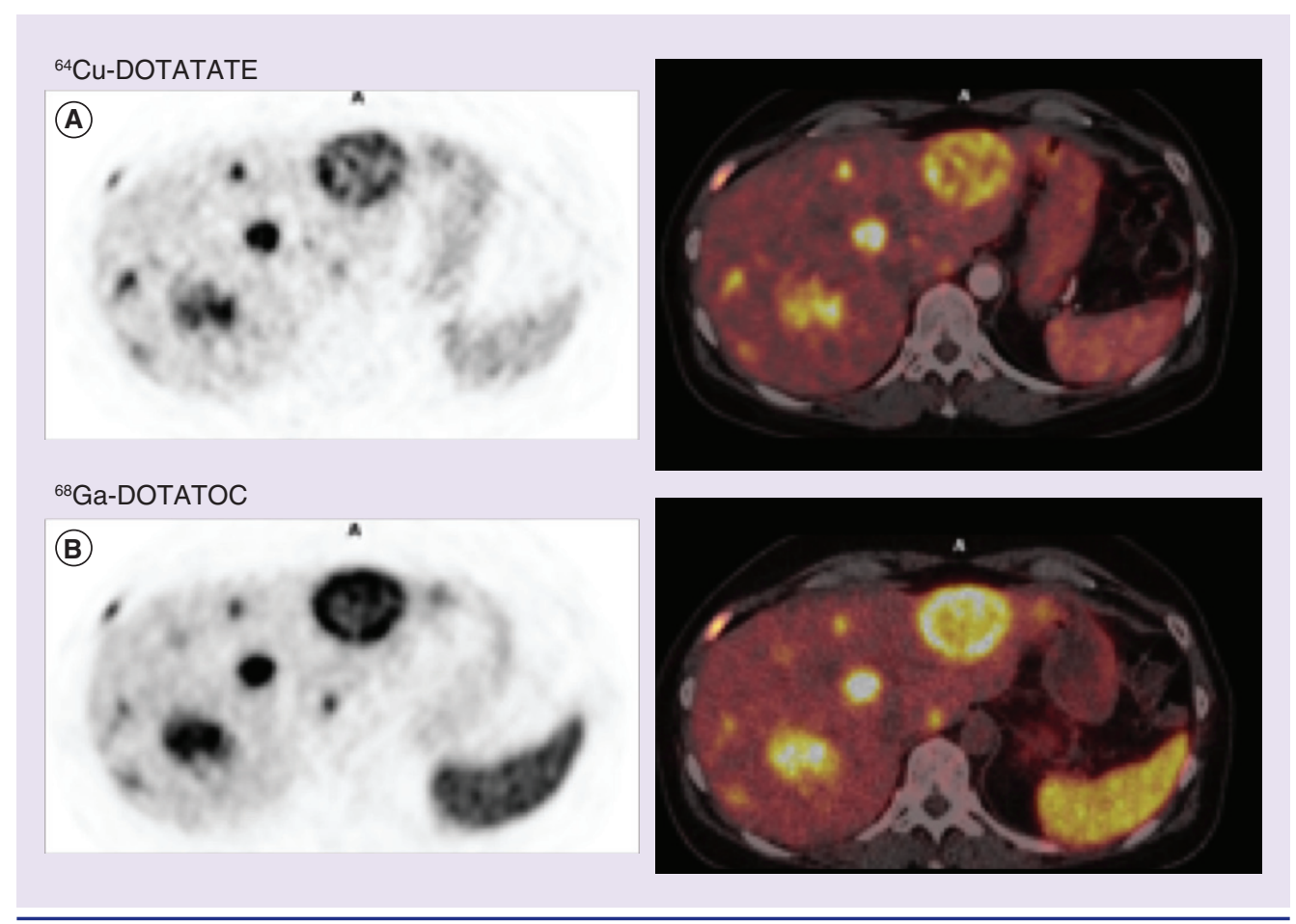

Figure 2. Imaging of the same neuroendocrine tumor liver lesions with ${ }^{64} \mathrm{Cu}$-DOTA-Tyr3octreotate and ${ }^{68} \mathrm{Ga}$-DOTA-Tyr3-octreotide. (A) ${ }^{64} \mathrm{Cu}$-DOTATATE; (B) ${ }^{68} \mathrm{Ga}$-DOTATOC. Please note the greater detail in ${ }^{64} \mathrm{Cu}$-DOTATATE images, probably due to differences in the positron ranges of ${ }^{64} \mathrm{Cu}$. DOTATATE: DOTA-Tyr3-octreotate; DOTATOC: DOTA-Tyr3-octreotide. 
Lung NETs

The distribution of somatostatin receptors in bronchial carcinoids was studied by Reubi and Waser [51]. sst1 and sst 2 were detected in $70 \%$ of tumors. sst 2 had the highest density, sst 3 and sst 4 were virtually undetected and sst 5 was found in $20 \%$ and with low density. This distribution might favor the use of DOTATATE, since it is the somatostatin analog with the highest sst 2 affinity.

Kayani et al. examined 18 pulmonary NET patients with ${ }^{68} \mathrm{Ga}$-DOTATATE and found a sensitivity of only $72 \%$ (Table 4) [57]. However, the false-negative tumors were all high-grade tumors that were positive on ${ }^{18} \mathrm{~F}$-fluorodeoxyglucose (FDG) scans, while the typical bronchial carcinoids had high and selective uptake [57]. Ambrosini et al. also found $100 \%$ sensitivity and specificity for ${ }^{68} \mathrm{Ga}$-DOTANOC in nine patients with typical, well-differentiated pulmonary NETs and two postoperation patients without tumors (Table 5) [62]. Using ${ }^{68} \mathrm{Ga}$-DOTATOC, Jindal et al. showed that typical carcinoids had a higher uptake than atypical ones, and additional lesions that were not seen on CT were found as well [71].

Thus, all three of the tracers had an equally high sensitivity for the typical bronchial carcinoids, while only some of the high-grade tumors were visualized and had a lower uptake of tracer.

\section{Liver metastases}

The extent of liver metastasis is often a determinant for the choice of treatment. Options such as chemoembolization, surgical liver resection, radionuclide treatment or liver transplantation are highly dependent on the amount and localization of liver metastases.

The amount of physiological uptake of a tracer in the liver might make a difference between the performances of the different somatostatin receptor PET tracers. However, the ratio between tumor and normal tissue uptake was approximately 3 for both ${ }^{68} \mathrm{Ga}$-DOTANOC [48] and ${ }^{68} \mathrm{Ga}$-DOTATOC (Table 2) [47]. In one of the few direct comparison studies, when using ${ }^{68} \mathrm{Ga}$-DOTANOC, Wild et al. detected significantly more liver lesions than when using ${ }^{68} \mathrm{Ga}$-DOTATATE, and the tumor-to-background ratios were calculated to be 2.7 and 2.0, respectively (Tables 4 \& 5) [60].

\section{Bone metastases}

The gold standard for detecting bone metastases is either with ${ }^{99 \mathrm{~m}} \mathrm{Tc}$-dicarboxy propane diphosphonate or the PET tracer ${ }^{18} \mathrm{~F}-\mathrm{NaF}$. The detection of bone metastases is important since they are associated with poorer prognosis [72], and extended surgery is contraindicated in patients with known bone metastases [73].

Putzer et al. scanned 51 patients with ${ }^{68} \mathrm{Ga}$-DOTATOC and a conventional bone scintigraphy $\left({ }^{99 \mathrm{~m}} \mathrm{Tc}\right.$-dicarboxy propane diphosphonate) or ${ }^{18} \mathrm{~F}-\mathrm{NaF}$ (Table 3) [53]. ${ }^{68} \mathrm{Ga}-\mathrm{DOTATOC}$ proved to be more accurate than both CT and bone scintigraphies. The sensitivity of ${ }^{68} \mathrm{Ga}$-DOTATOC for detecting bone metastases was $97 \%$ and the specificity was $92 \%$. The conventional bone scans did not reveal any additional bone metastases in any patients compared with ${ }^{68} \mathrm{Ga}$-DOTATOC [53].

Ambrosini et al. detected 44 patients with bone metastases among 223 patients with confirmed NETs using ${ }^{68} \mathrm{Ga}-\mathrm{DOTANOC}$ versus 35 patients when using CT alone (Table 5) [63]. With the incorporation of follow-up as a reference, sensitivity and specificity values of $100 \%$ were found [63].

Gabriel et al. compared ${ }^{68} \mathrm{Ga}$-DOTATOC with ${ }^{99 m}$ Tc-hydrazinonicotinyl-Tyr(3)-octreotide (HYNIC-TOC) and/or ${ }^{111}$ In-DTPA-OC and CT in 84 patients and found a significantly better overall diagnostic efficacy with ${ }^{68}$ Ga-DOTATOC ( $\mathrm{p}=0.001$ ) (Table 3) [26]. The difference in the detection rate was most pronounced for bone metastases. Of 116 ${ }^{68} \mathrm{Ga}$-DOTATOC PET-positive bone lesions, SPECT delineated 84 lesions (72.5\%) and CT delineated only 58 lesions (50\%) [26].

In a lesion-to-lesion analysis in 18 patients scanned with both ${ }^{68} \mathrm{Ga}-\mathrm{DOTANOC}$ and ${ }^{68} \mathrm{Ga}$-DOTATATE, Wild et al. reported ${ }^{68} \mathrm{Ga}$-DOTATATE to detect significantly more bone lesions compared with ${ }^{68} \mathrm{Ga}$-DOTANOC (89 vs 82) (Tables 4 \& 5) [60]. ${ }^{68}$ Ga-DOTATATE had a lower bone marrow activity than ${ }^{68} \mathrm{Ga}$-DOTANOC, resulting in a higher tumorto-background activity for bone metastases with ${ }^{68} \mathrm{Ga}$-DOTATATE.

\section{Unknown primaries}

A well-known situation involves finding metastases of the liver as the first clinical presentation of NETs without any evidence of the primary tumor. In a study by Prasad et al., 59 NET patients with unknown primary tumors were scanned with ${ }^{68} \mathrm{Ga}$-DOTANOC PET/CT [74]. The primary tumor site was localized in 35 out of 59 patients (59\%), while CT alone only 
found 12 out of 59 primary tumor sites (20\%). Thus, PET found almost three-times as many primary tumor sites as CT alone [74]. Similar results were obtained by Naswa et al. with ${ }^{68} \mathrm{Ga}$-DOTANOC, which found 12 out of 20 primary tumors $(60 \%)$ in NET patients with unknown primary tumors [75]. Furthermore, they found a significant correlation between the primary tumor $S U V_{\text {max }}$ and the $S U V_{\text {max }}$ of their metastases [75].

Using ${ }^{68} \mathrm{Ga}$-DOTATATE, Lapińska et al. found the primary tumor in five out of 14 patients (36\%) with unknown primary cancers [76]. No direct comparisons of the efficacy for identifying unknown primary tumors between the tracers have been published. A quantitative determination of the amount of the different somatostatin subtypes in the identified metastases of an unknown primary NET could potentially help us to determine what tracer is most likely to be most sensitive in individual cases. This requires that metastases and primary tumors show the same phenotypes.

\section{Unusual NETs}

Somatostatin receptor PET with ${ }^{68} \mathrm{Ga}$-DOTANOC has been described in a small series of rare NETs [77]. ${ }^{68} \mathrm{Ga}$-DOTANOC was positive, showing at least one positive lesion in seven out of 14 cases. It was considered useful in 12 out of 14 cases, but it was considered inconclusive in two cases, one of uterine and one of ovarian localization. The useful cases included three paragangliomas (all positive), three prostate NETs (one positive and two negative), two uterine cases and a single breast, lymphoma, ear and kidney NET.

\section{Impact on clinical decision-making}

The crucial question whenever a new diagnostic modality is evaluated is whether there is a clinical impact on treatment, control or prognosis for patients. The use of somatostatin receptor PET scanning as an addition to conventional imaging by CT or MRI changed treatment in $20-60 \%$ of cases $[64,78,79]$, especially those concerning the choice of treatment with PRRT [80]. There is therefore no doubt that NET patients benefit from the use of somatostatin receptor PET imaging. No studies have determined a significant clinical gain of using one tracer over the others among the most used tracers $-{ }^{68} \mathrm{Ga}$-DOTATOC, ${ }^{68} \mathrm{Ga}$-DOTATE and ${ }^{68} \mathrm{Ga}$-DOTANOC.

\section{Dosimetry \& the best time to scan}

In the process of selecting the optimal tracer for somatostatin receptor imaging, the amount of radiation given to the patient should also be considered, especially since NET patients often receive multiple scans during their lifetime. Differences in radionuclide, affinity and excretion of the somatostatin receptor tracers also lead to variable radiation burden to the patients. A comparison of absorbed doses in the most exposed organs and the effective doses for the whole body is shown in Table 6 for the most commonly used and one promising new tracer $[43,81-86]$.

For ${ }^{68} \mathrm{Ga}$-emitting somatostatin receptor tracers, the most exposed organ is the spleen, followed by the bladder, kidneys and liver. The primary excretion route is renal. For ${ }^{64} \mathrm{Cu}$-DOTATATE, uptake in the spleen is lower compared with its ${ }^{68} \mathrm{Ga}$ counterparts (see Figure 2); instead, the liver seems to be more exposed [43]. All of the somatostatin receptor PET tracers possess a dosimetric advantage for the patient compared with the $\gamma$-emitting tracers ${ }^{111}$ In-DTPA-OC and ${ }^{111} \mathrm{In}$-DOTATOC, both of which result in approximately twice the radiation dose to the patients (Table 6) [86].

The scan times used for ${ }^{68} \mathrm{Ga}$-PET somatostatin receptor tracers are 30-100 min after the injection of the tracer. This allows sufficient time for the tracer to accumulate in the tumors and background clearance, taking the short half-life of ${ }^{68} \mathrm{Ga}(68 \mathrm{~min})$ into account [24,26]. If ${ }^{64} \mathrm{Cu}$-coupled tracers are used, the possibility of later imaging exists, because of its longer half-life $(12.7 \mathrm{~h})$. Scans from 1 to $24 \mathrm{~h}$ postinjection have been evaluated, and late scans might give some additional findings in selected cases [43].

\section{Addition of anatomical imaging}

Somatostatin receptor PET scanning is often performed together with a CT scan in order to provide anatomical information regarding the discovered lesions. Low-dose CT can be used to spare the patient from the full-dose radiation of a diagnostic CT scan, especially during long-term follow-up. For the initial diagnostic work-up, staging and treatment response, monitoring the highest accuracy must be pursued, and a diagnostic CT scan using a triple-phase CT protocol is recommended or, if possible, a combination of MRI and the PET modality could be used, since this gives very high accuracy.

Ruf et al. compared the sensitivities and accuracies of ${ }^{68} \mathrm{Ga}$-DOTATOC and each of the three 
Table 6. Absorbed doses in the most exposed organs and the effective doses of somatostatin receptor tracers.

\begin{tabular}{|c|c|c|c|c|c|c|}
\hline Organ/dose & $\begin{array}{l}{ }^{68} \mathrm{Ga}-\mathrm{DOTANOC} \\
{[81]}\end{array}$ & $\begin{array}{l}{ }^{68} \mathrm{Ga} \text {-DOTATOC } \\
{[82]}\end{array}$ & $\begin{array}{l}{ }^{68} \mathrm{Ga} \text {-DOTATATE } \\
{[83]}\end{array}$ & $\begin{array}{l}{ }^{64} \mathrm{Cu} \text {-DOTATATE } \\
{[43]}\end{array}$ & $\begin{array}{l}{ }^{111} \text { In-DTPAOC } \\
{[86]}\end{array}$ & $\begin{array}{l}{ }^{111} \text { In-DOTATOC } \\
{[86]}\end{array}$ \\
\hline Kidneys (mGy/MBq) & 0.09 & 0.22 & 0.09 & 0.14 & 0.47 & 0.50 \\
\hline Liver (mGy/MBq) & 0.03 & 0.07 & 0.05 & 0.16 & 0.07 & 0.05 \\
\hline Spleen (mGy/MBq) & 0.07 & 0.24 & 0.28 & 0.12 & 0.36 & 0.47 \\
\hline Bladder (mGy/MBq) & 0.08 & 0.07 & 0.13 & 0.04 & 0.19 & 0.16 \\
\hline Effective dose (mSv/MBq) & 0.02 & 0.02 & 0.03 & 0.03 & 0.05 & 0.05 \\
\hline Typical administed dose (MBq) & $120-200$ & $120-200$ & $120-200$ & $180-220$ & $111-222$ & $140-200$ \\
\hline $\begin{array}{l}\text { Radiation burden at a typical } \\
\text { dose (mSv) }\end{array}$ & $2.0-3.3$ & $2.8-4.6$ & $3.0-5.1$ & $5.7-6.9$ & $5.6-11.1$ & $7.0-10.0$ \\
\hline
\end{tabular}

scans from a triple-phase CT protocol in 51 NET patients [87]. PET proved to be the most accurate and robust submodality. For correct topographic assignment of the PET foci, the portal venous phase and venous phase showed comparable sensitivities and the arterial-phase CT was the least prominent, but the most robust. However, each of the scans showed exclusive foci detection and together delivered synergistic information [87]. Enhancement with contrast in a ${ }^{68} \mathrm{Ga}$-DOTATOC PET/CT study increased the sensitivity from 92 to $99 \%$ [88].

The combination of PET with MRI increased the sensitivity for liver metastases (especially lesions of $<1 \mathrm{~cm}$ ) from 74 to $91 \%$, and specificity was raised from 88 to $96 \%$ compared with PET/ CT [89]. A combination of diffusion-weighted imaging (DWI) and contrast-enhanced MRI (with hepatocyte-specific contrast) improved the specificity [89]. In addition, Giesel et al. found more liver metastases with MRI compared with CT [90], while the two modalities of ${ }^{68} \mathrm{Ga}$-DOTATOC/low-dose CT and ${ }^{68} \mathrm{Ga}$-DOTATOC/MRI performed equally in a study by Gaertner et al. [91].

Further to strict anatomical information, additional information might be attainable from MRI due to functional features as DWI and spectroscopy both known to be prognostic in various cancer forms. We have seen several cases of NET liver metastases presenting highly different lesions on DWI and PET scans, and one case has been published [92]. For patients who are not suitable for imaging with contrastenhanced CT, MRI seems promising for lesion detection [93].

The latest ENETS consensus guidelines state that a high-resolution, three-phase CT in combination with PET using a ${ }^{68} \mathrm{Ga}$ somatostatin receptor PET tracer should be performed in
NET patients with unknown primary tumors. Furthermore, MRI is considered to be superior to CT in the detection and follow-up of liver metastases, so if the CT scan of liver metastases is inconclusive, T2-weighted, thinslice, dynamic, gadolinium-enhanced MRI is recommended [30].

\section{Comparisons with other PET tracers \\ - Comparison with ${ }^{18} \mathrm{~F}-\mathrm{L}-$ dihydroxyphenylalanine}

Many neuroendocrine cells take up and decarboxylate amino acid precursors, such as L-dihydroxyphenylalanine (DOPA). This feature enables imaging with ${ }^{18} \mathrm{~F}$-DOPA. ${ }^{18} \mathrm{~F}$-DOPA scanning provides information regarding the biochemistry of the tumor, rather than how well it expresses somatostatin receptors. However, in a comparison between ${ }^{68} \mathrm{Ga}-\mathrm{DOTANOC}$ and ${ }^{18} \mathrm{~F}$-DOPA in 13 patients with GEP NETs or lung NETs, the ${ }^{68} \mathrm{Ga}$-DOTANOC scan detected 71 lesions compared with only 45 lesions being found by ${ }^{18} \mathrm{~F}$-DOPA PET scans [61]. In another study of 15 patients, ${ }^{68} \mathrm{Ga}-\mathrm{DOTANOC}$ and ${ }^{18} \mathrm{~F}$-DOPA showed comparable results when matched on a patient basis, but on a lesion basis, ${ }^{68} \mathrm{Ga}$-DOTANOC was again superior, even though the patients had NETs favoring amine precursor uptake and decarboxylation, such as pheochromocytomas, paragangliomas and medullary thyroid cancers [94].

Haug et al. found a patient-based sensitivity of $96 \%$ for ${ }^{68} \mathrm{Ga}$-DOTATATE compared with 56\% for ${ }^{18} \mathrm{~F}$-DOPA in 25 patients with well-differentiated metastatic NETs. However, a correlation between the SUV $\mathrm{max}_{\text {max }}$ of ${ }^{18} \mathrm{~F}-\mathrm{DOPA}$ and plasma serotonin in patients who were positive for ${ }^{18} \mathrm{~F}$-DOPA was found, suggesting a role for ${ }^{18} \mathrm{~F}-\mathrm{DOPA}$ scans in serotonin-secreting tumors that are not visible on somatostatin receptor PET [58]. 


\section{- Comparison with ${ }^{18} \mathrm{~F}-\mathrm{FDG}$}

${ }^{18} \mathrm{~F}-\mathrm{FDG}$ PET has recently been shown to provide prognostic information regarding survival from NETs [95]. Binderup et al. found $58 \%$ of 96 patients to be positive on ${ }^{18}$ F-FDG PET [96]. These were mainly found in the group of patients with the highest-proliferating tumors (Ki-67 >15\%); among these, $92 \%$ were FDG positive. Similarly, Kayani et al. found a significant correlation between the uptake of ${ }^{68} \mathrm{Ga}$-DOTATATE or ${ }^{18} \mathrm{~F}-\mathrm{FDG}$ and histological tumor grade on histology [56]. In low-grade NETs, 97 lesions were found by ${ }^{68} \mathrm{Ga}$-DOTATATE and no lesions were found by ${ }^{18} \mathrm{~F}$-FDG, while ${ }^{18} \mathrm{~F}$-FDG detected 72 lesions compared with no lesions by ${ }^{68} \mathrm{Ga}$-DOTATATE in high-grade NETs.

Oh et al. investigated somatostatin receptor status and glucose metabolism in a group of patients with progressive, metastasized NETs [97]. Only approximately $60 \%$ of the lesions showed matching lesions as detected by both ${ }^{68} \mathrm{Ga}$-DOTANOC and ${ }^{18} \mathrm{~F}$-FDG.

Wild et al. found that even though the SUV decreased for both ${ }^{68} \mathrm{Ga}$-DOTATOC and ${ }^{68} \mathrm{Ga}$-DOTATATE as the tumor grade increased, they both detected significantly more G3 lesions (82 and $90 \%$, respectively) than ${ }^{18} \mathrm{~F}-\mathrm{FDG}$ PET (58\%) [60].

Since the most aggressive NETs are often negative on somatostatin receptor imaging and often positive on ${ }^{18} \mathrm{~F}$-FDG PET, there may be a role for the diagnostic use of ${ }^{18} \mathrm{~F}-\mathrm{FDG}$ PET in somatostatin receptor imaging-negative cases.

\section{Conclusion}

It is now 25 years since $\gamma$-camera-based somatostatin receptor imaging was introduced and improved diagnosis and patient management in NETs. Recently, several PET tracers, most notably ${ }^{68} \mathrm{Ga}$-DOTATOC, ${ }^{68} \mathrm{Ga}$-DOTATATE and ${ }^{68} \mathrm{Ga}$-DOTANOC, have been introduced as substitutes for $\gamma$-emitting tracers. The bulk of the literature has clearly proven that these PET tracers are superior to the $\gamma$-emitting ${ }^{111}$ In-DTPA-OC. On the whole, the ${ }^{68} \mathrm{Ga}$-based tracers perform similarly and so their choice is best made based on past experience and matching it with PRRT. Accordingly, evidence now supports the shift to somatostatin receptor PET tracers in the clinical routine, as has largely happened, especially in Europe. So far, ${ }^{18}$ F-labeled somatostatin receptor tracers have not emerged at a larger scale. Two ${ }^{64} \mathrm{Cu}$-based somatostatin receptor
PET tracers have been described, most recently ${ }^{64} \mathrm{Cu}$-DOTATATE. In theory, ${ }^{64} \mathrm{Cu}$-labeled tracers should provide better resolutions than ${ }^{68} \mathrm{Ga}$-labeled tracers, but whether this translates into improved diagnostic performance remains to be shown.

\section{Future perspective}

Somatostatin receptor imaging should be performed in PET whenever possible. Whereas the ${ }^{68} \mathrm{Ga}$-based somatostatin analog tracers have paved the way for using PET instead of SPECT for somatostatin receptor imaging, we foresee that labeling with radionuclides such as ${ }^{18} \mathrm{~F}$ and ${ }^{64} \mathrm{Cu}$, as well as new ligands (e.g., receptor antagonists), will further improve the value and use of these tracers. In addition, tracers that specifically target subtypes of NET (e.g., GLP-1 for the imaging of insulinomas) may become routine in the future. Interesting results have been reported using an analog to the GLP-1 receptor, exendin 4 , either coupled to ${ }^{111} \mathrm{In}$ or ${ }^{68} \mathrm{Ga}$ for imaging insulinomas [98-100]. Evidence that the somatostatin receptor and GLP-1 receptor distributions in benign and malignant insulinomas are different has been presented $[101,102]$, and a greater sensitivity for detecting insulinomas overall might therefore be achievable with a combination of tracers in the same way as is observed with FDG and somatostatin receptor PET for poorly differentiated G3 NETs.

Financial \& competing interests disclosure The generous support of the research into the PET imaging of neuroendocrine tumors in form of unrestriced grants from the Danish National Advanced Technology Foundation, the John and Birthe Meyer Foundation, the Danish Medical Research Council, the Rigshospitalets Research Foundation, the Svend Andersen Foundation, the AP Moller Foundation, the Novo Nordisk Foundation, the Lundbeck Foundation and the Danish Cancer Society is gratefully acknowledged. The authors have no other relevant affliations or financial involvement with any organization or entity with a financial interest in or financial conflict with the subject matter or materials discussed in the manuscript apart from those disclosed.

No writing assistance was utilized in the production of this manuscript.

\section{Open access}

This work is licensed under the Creative Commons Attribution-NonCommercial 3.0 Unported License. To view a copy of this license, visit http://creativecommons.org/ licenses/by-nc-nd/3.0/ 


\section{EXECUTIVE SUMMARY}

\section{Neuroendocrine tumors}

- Neuroendocrine tumors (NETs) have seen a fivefold increase in incidence since 1973.

- Lung (25\%) and gastro-entero-pancreatic NETs (75\%) are the most frequent.

- The overexpression of five different subtypes of somatostatin receptors is seen in $80-100 \%$ of NETs.

\section{PET versus $\gamma$-cameras}

- $\quad$ PET has a better sensitivity and resolution compared with imaging by SPECT.

- $\quad$ PET makes the quantification of tracer uptake possible.

- Lower radiation doses to the patients are possible when using PET tracers.

- Lower costs and greater patient comfort are possible with PET.

\section{Somatostatin receptor PET tracers}

- $\quad{ }^{68} \mathrm{Ga}$-DOTA-Tyr3-octreotide (DOTATOC), ${ }^{68} \mathrm{Ga}$-DOTA-Tyr3-octreotate (DOTATATE) and ${ }^{68} \mathrm{Ga}-\mathrm{DOTA}-\mathrm{I-Nal3-octreotide}$ (DOTANOC) are the most frequently used tracers for somatostatin receptor PET.

- A few ${ }^{18} \mathrm{~F}$ - or ${ }^{64} \mathrm{Cu}$-labeled tracers have been tested.

- ${ }^{68} \mathrm{Ga}$ and ${ }^{18} \mathrm{~F}$ have short half-lives (68 and $110 \mathrm{~min}$, respectively), while ${ }^{64} \mathrm{Cu}$ (half-life: $12.7 \mathrm{~h}$ ) makes late imaging possible.

- $\quad{ }^{18} \mathrm{~F}$ and ${ }^{64} \mathrm{Cu}$ have a shorter positron range than ${ }^{68} \mathrm{Ga}$, which translates into better resolution.

Affinity of the somatostatin receptor PET tracers

- Ga-DOTATOC has affinity towards sst2 and sst5.

- Ga-DOTATATE only has affinity towards sst2. The affinity is tenfold higher than with Ga-DOTATOC or Ga-DOTANOC.

- Ga-DOTANOC has affinity towards sst2, sst5 and sst3. The affinity towards sst5 is tenfold higher than with Ga-DOTATOC.

- The most abundant receptor is sst2, which is expressed in $70-90 \%$ of NETs.

Head-to-head comparison: only a few such studies exist

- ${ }^{68} \mathrm{Ga}$-DOTATATE versus ${ }^{68} \mathrm{Ga}$-DOTATOC: patient- or region-based comparisons showed no differences.

- ${ }^{68} \mathrm{Ga}$-DOTATATE versus ${ }^{68} \mathrm{Ga}$-DOTANOC: ${ }^{68} \mathrm{Ga}$-DOTATATE found fewer lesions in one study and more in another. Patientbased comparison showed no differences.

- ${ }^{68} \mathrm{Ga}$-DOTALAN found fewer lesions than with ${ }^{68} \mathrm{Ga}$-DOTATOC and ${ }^{68} \mathrm{Ga}$-DOTATATE.

Performance of somatostatin receptor PET tracers: noncomparative studies

- Patient-based sensitivities for the three most used tracers are: ${ }^{68} \mathrm{Ga}-\mathrm{DOTATOC}: 78-100 \%$; ${ }^{68} \mathrm{Ga}-\mathrm{DOTATATE}: 72-100 \%$; and ${ }^{68}$ Ga-DOTANOC: $68-100 \%$.

\section{Comparison with other PET tracers}

- $\quad{ }^{18} \mathrm{~F}$-L-dihydroxyphenylalanine found the fewest lesions in studies comparing it with ${ }^{68} \mathrm{Ga}$-DOTANOC or ${ }^{68} \mathrm{Ga}-\mathrm{DOTATATE}$.

- ${ }^{18} \mathrm{~F}$-fluorodeoxyglucose (FDG) uptake is seen in high-grade lesions and not in low-grade lesions, which is the opposite in somatostatin receptor PET, making ${ }^{18} \mathrm{~F}-\mathrm{FDG}$ suitable for aggressive cases.

- $\quad{ }^{18} \mathrm{~F}-\mathrm{FDG}$ provides prognostic information in NETs.

\section{Conclusion \& future perspective}

- Somatostatin receptor imaging should be PET based.

- ${ }^{68} \mathrm{Ga}$-DOTATOC, ${ }^{68} \mathrm{Ga}$-DOTATATE and ${ }^{68} \mathrm{Ga}$-DOTANOC all perform well and the choice is best made based on experience with the tracer and matching it with peptide receptor radionuclide therapy.

- $\quad{ }^{18} \mathrm{~F}$ - and ${ }^{64} \mathrm{Cu}$-labeled somatostatin receptors have not emerged into routine practice so far. They have potential for a better resolution than with ${ }^{68} \mathrm{Ga}$-labeled tracers.

- $\quad$ PET tracers using new somatostatin analogs as radioligands might improve affinity and sensitivity further. 


\section{References}

Papers of special note have been highlighted as:

- of interest; $\bullet$ of considerable interest

1 Yao JC, Hassan M, Phan A et al. One hundred years after 'carcinoid': epidemiology of and prognostic factors for neuroendocrine tumors in 35,825 cases in the United States. J. Clin. Oncol. 26(18), 3063-3072 (2008).

- Fraenkel M, Kim MK, Faggiano A, de Herder WW, Valk GD. Incidence of gastroenteropancreatic neuroendocrine tumours: a systematic review of the literature. Endocr. Relat. Cancer 21(3), R152-R163 (2014).

3 Rindi G, Arnold R, Bosman FT et al. Nomenclature and classification of neuroendocrine neoplasms of the digestive system. In: WHO Classification of Tumours of the Digestive System (4th Edition). Bosman TF, Carneiro F, Hruban RH, Theise ND (Eds). International Agency for Research on Cancer $>_{15}$ (IARC), France, 13-14 (2010).

4 Klöppel G. Classification and pathology of gastroenteropancreatic neuroendocrine neoplasms. Endocr. Relat. Cancer 18 (Suppl. 1), S1-S16 (2011).

-5 Rindi G, Klöppel G, Alhman H et al. TNM staging of foregut (neuro)endocrine tumors: a consensus proposal including a grading system. Virchows Arch. 449(4), 395-401 (2006).

-6 Rindi G, Klöppel G, Couvelard A et al. TNM staging of midgut and hindgut (neuro) endocrine tumors: a consensus proposal including a grading system. Virchows Arch. 451(4), 757-762 (2007).

7 Travis WD. The concept of pulmonary neuroendocrine tumour. In: Pathology and Genetics of Tumours of the Lung, Pleura, Thymus and Heart. World Health Organization Classification of Tumours. Travis WD, Brambilla E, Müller-Hermelink HK, Harris CC (Eds). International Agency for Research on Cancer (IARC), France, 19-20 (2004).

-8 Rindi G, Klersy C, Inzani F et al. Grading the neuroendocrine tumors of the lung: an evidence-based proposal. Endocr. Relat. Cancer 21(1), 1-16 (2014).

\. Eriksson B, Oberg K. Summing up 15 years of somatostatin analog therapy in neuroendocrine tumors: future outlook. Ann. Oncol. 10(Suppl. 2), S31-S38 (1999).

10 Modlin IM, Pavel M, Kidd M, Gustafsson BI. Review article: somatostatin analogues in the treatment of gastroenteropancreatic neuroendocrine (carcinoid) tumours. Aliment. Pharmacol. Ther. 31(2), 169-188 (2010).

- 11 Rinke A, Müller H-H, Schade-Brittinger C et al. Placebo-controlled, double-blind, prospective, randomized study on the effect of octreotide LAR in the control of tumor growth in patients with metastatic neuroendocrine midgut tumors: a report from the PROMID Study Group. J. Clin. Oncol. 27(28), 4656-4663 (2009).

- 12 Hoyer D, Bell GI, Berelowitz M et al. Classification and nomenclature of somatostatin receptors. Trends Pharmacol. Sci. 16(3), 86-88 (1995).

13 Kubota A, Yamada Y, Kagimoto S et al. Identification of somatostatin receptor subtypes and an implication for the efficacy of somatostatin analogue SMS 201-995 in treatment of human endocrine tumors. J. Clin. Invest. 93(3), 1321-1325 (1994).

14 Reubi JC. Somatostatin and other peptide receptors as tools for tumor diagnosis and treatment. Neuroendocrinology 80 (Suppl. 1), 51-56 (2004).

15 Binderup T, Knigge U, Mellon Mogensen A, Palnaes Hansen C, Kjær A. Quantitative gene expression of somatostatin receptors and noradrenaline transporter underlying scintigraphic results in patients with neuroendocrine tumors. Neuroendocrinology 87(4), 223-232 (2008).

16 Reubi JC, Waser B, Schaer JC, Laissue JA. Somatostatin receptor sst $1-$ sst 5 expression in normal and neoplastic human tissues using receptor autoradiography with subtypeselective ligands. Eur. J. Nucl. Med. 28(7), 836-846 (2001).

17 Modlin IM, Oberg K, Chung DC et al. Gastroenteropancreatic neuroendocrine tumours. Lancet Oncol. 9(1), 61-72 (2008).

$\checkmark 18$ Bauer W, Briner U, Doepfner W et al. SMS 201-995: a very potent and selective octapeptide analogue of somatostatin with prolonged action. Life Sci. 31(11), 1133-1140 (1982).

-19 Krenning EP, Bakker WH, Breeman WA et al. Localisation of endocrine-related tumours with radioiodinated analogue of somatostatin. Lancet 1(8632), 242-244 (1989).

- 20 Krenning EP, Kwekkeboom DJ, Bakker WH et al. Somatostatin receptor scintigraphy with [111 In-DTPA-D-Phe1]- and [ $\left.{ }^{123} \mathrm{I}-\mathrm{Tyr} 3\right]-$ octreotide: the Rotterdam experience with more than 1000 patients. Eur. J. Nucl. Med. 20(8), 716-731 (1993).

Campana D, Ambrosini V, Pezzilli R et al. Standardized uptake values of ${ }^{68} \mathrm{Ga}-$ DOTANOC PET: a promising prognostic tool in neuroendocrine tumors. J. Nucl. Med. 51(3), 353-359 (2010).

22 Krausz Y, Freedman N, Rubinstein R et al. ${ }^{68} \mathrm{Ga}$-DOTA-NOC PET/CT imaging of neuroendocrine tumors: comparison with ${ }^{111}$ In-DTPA-octreotide (OctreoScan $\left.{ }^{\circledR}\right) . M o l$. Imaging Biol. 13(3), 583-593 (2011).

23 Buchmann I, Henze M, Engelbrecht $\mathrm{S}$ et al. Comparison of ${ }^{68} \mathrm{Ga}$-DOTATOC PET and ${ }^{111}$ In-DTPAOC (Octreoscan) SPECT in patients with neuroendocrine tumours. Eur. J. Nucl. Med. Mol. Imaging 34(10), 1617-1626 (2007).

-24 Hofman MS, Kong G, Neels OC, Eu P, Hong E, Hicks RJ. High management impact of Ga-68 DOTATATE (GaTate) PET/CT for imaging neuroendocrine and other somatostatin expressing tumours. J. Med. Imaging Radiat. Oncol. 56(1), 40-47 (2012).

-25 Hofmann M, Maecke H, Börner R et al. Biokinetics and imaging with the somatostatin receptor PET radioligand ${ }^{68} \mathrm{Ga}$-DOTATOC: preliminary data. Eur. J. Nucl. Med. 28(12), 1751-1757 (2001).

26 Gabriel M, Decristoforo C, Kendler D et al. ${ }^{68} \mathrm{Ga}$-DOTA-Tyr3-octreotide PET in neuroendocrine tumors: comparison with somatostatin receptor scintigraphy and CT. J. Nucl. Med. 48(4), 508-518 (2007).

\27 Srirajaskanthan R, Kayani I, Quigley AM, Soh J, Caplin ME, Bomanji J. The role of ${ }^{68} \mathrm{Ga}$-DOTATATE PET in patients with neuroendocrine tumors and negative or equivocal findings on ${ }^{111}$ In-DTPA-octreotide scintigraphy. J. Nucl. Med. 51(6), 875-882 (2010).

-28 Schreiter NF, Brenner W, Nogami M et al. Cost comparison of ${ }^{111}$ In-DTPA-octreotide scintigraphy and ${ }^{68} \mathrm{Ga}$-DOTATOC PET/CT for staging enteropancreatic neuroendocrine tumours. Eur. J. Nucl. Med. Mol. Imaging 39(1), 72-82 (2012).

29 Al-Nahhas A, Win Z, Szyszko T et al. Gallium-68 PET: a new frontier in receptor cancer Imaging Anticancer Res. 27(6B), 4087-4094 (2007).

30 Pavel M, Baudin E, Couvelard A et al. ENETS Consensus Guidelines for the management of patients with liver and other distant metastases from neuroendocrine neoplasms of foregut, midgut, hindgut, and unknown primary. Neuroendocrinology 95(2), 157-176 (2012).

- 31 Pape U-F, Perren A, Niederle B et al. ENETS Consensus Guidelines for the management of patients with neuroendocrine neoplasms from the jejuno-ileum and the appendix including goblet cell carcinomas. Neuroendocrinology 95(2), 135-156 (2012).

- 32 Falconi M, Bartsch DK, Eriksson B et al. ENETS Consensus Guidelines for the management of patients with digestive neuroendocrine neoplasms of the digestive 
system: well-differentiated pancreatic non-functioning tumors.

Neuroendocrinology 95(2),120-134 (2012).

33 Caplin M, Sundin A, Nillson O et al. ENETS Consensus Guidelines for the management of patients with digestive neuroendocrine neoplasms: colorectal neuroendocrine neoplasms. Neuroendocrinology 95(2), 88-97 (2012).

\$4 Jensen RT, Cadiot G, Brandi ML et al. ENETS Consensus Guidelines for the management of patients with digestive neuroendocrine neoplasms: functional pancreatic endocrine tumor syndromes. Neuroendocrinology 95(2), 98-119 (2012).

35 Reubi JC, Schär JC, Waser B et al. Affinity profiles for human somatostatin receptor subtypes SST1-SST5 of somatostatin radiotracers selected for scintigraphic and radiotherapeutic use. Eur. J. Nucl. Med. 27(3), 273-282 (2000).

-. Interesting and thorough basis for the different affinities of the most used neuroendocrine tumor (NET) PET tracers.

-36 Reubi JC, Erchegyi J, Cescato R, Waser B, Rivier JE. Switch from antagonist to agonist after addition of a DOTA chelator to a somatostatin analog. Eur. J. Nucl. Med. Mol. Imaging 37(8), 1551-1558 (2010).

-37 Waser B, Tamma M-L, Cescato R, Maecke HR, Reubi JC. Highly efficient in vivo agonist-induced internalization of sst 2 receptors in somatostatin target tissues. $J$. Nucl. Med. 50(6), 936-941 (2009).

-38 Cescato R, Schulz S, Waser B et al. Internalization of sst 2 , sst 3 , and sst 5 receptors: effects of somatostatin agonists and antagonists. J. Nucl. Med. 47(3), 502-511 (2006).

39 Ginj. M, Zhang H, Waser B et al. Radiolabeled somatostatin receptor antagonists are preferable to agonists for in vivo peptide receptor targeting of tumors. Proc. Natl Acad. Sci. USA 103(44), 1643616441 (2006).

40 Reubi JC. Old and new peptide receptor targets in cancer: future directions. Recent Results Cancer Res. 194, 567-576 (2013).

-41 Wild D, Fani M, Behe M et al. First clinical evidence that imaging with somatostatin receptor antagonists is feasible. J. Nucl. Med. 52(9), 1412-1417 (2011).

42 Anderson CJ, Dehdashti F, Cutler PD et al. ${ }^{64} \mathrm{Cu}$-TETA-octreotide as a PET imaging agent for patients with neuroendocrine tumors. J. Nucl. Med. 42(2), 213-221 (2001).

43 Pfeifer A, Knigge U, Mortensen J et al. Clinical PET of neuroendocrine tumors using
${ }^{64} \mathrm{Cu}$-DOTATATE: first-in-humans study. J. Nucl. Med. 53(8), 1207-1215 (2012).

44 Antunes P, Gin J. M, Zhang H et al. Are radiogallium-labelled DOTA-conjugated somatostatin analogues superior to those labelled with other radiometals? Eur. J. Nucl. Med. Mol. Imaging 34(7), 982-993 (2007).

- Presents an affinity profile for the somatostatin receptor subtypes of GaDOTANOC, among other comparisons.

45 Meisetschläger G, Poethko T, Stahl A et al. Gluc-Lys ([18 F]FP)-TOCA PET in patients with SSTR-positive tumors: biodistribution and diagnostic evaluation compared with [ ${ }^{111}$ In]DTPA-octreotide. J. Nucl. Med. 47(4), 566-573 (2006).

46 Prieto E, Domínguez-Prado I, García-Velloso MJ, Peñuelas I, Richter JÁ, Martí-Climent JM. Impact of time-of-flight and pointspread-function in SUV quantification for oncological PET. Clin. Nucl. Med. 38(2), 103-109 (2013).

47 Kroiss A, Putzer D, Decristoforo C et al. ${ }^{68} \mathrm{Ga}$-DOTA-TOC uptake in neuroendocrine tumour and healthy tissue: differentiation of physiological uptake and pathological processes in PET/CT. Eur. J. Nucl. Med. Mol. Imaging 40(12), 1800-1808. (2013).

- Valuable information regarding ${ }^{68} \mathrm{Ga}$ DOTATOC's distribution in normal and pathological tissues.

48 Prasad V, Baum RP. Biodistribution of the Ga-68 labeled somatostatin analogue DOTA-NOC in patients with neuroendocrine tumors: characterization of uptake in normal organs and tumor lesions. Q.J. Nucl. Med. Mol. Imaging 54(1), 61-67 (2010).

- Valuable information regarding ${ }^{68} \mathrm{Ga}-$ DOTANOC's distribution in normal and pathological tissues.

49 Kunikowska J, Królicki L, Pawlak D, Zerizer I, Mikołajczak R. Semiquantitative analysis and characterization of physiological biodistribution of ${ }^{68} \mathrm{Ga}$-DOTA-TATE PET/ CT. Clin. Nucl. Med. 37(11), 1052-1057 (2012).

- Valuable information regarding ${ }^{68} \mathrm{Ga}$ DOTATAE's distribution in normal and pathological tissues.

50 Krausz Y, Rubinstein R, Appelbaum L et al. Ga-68 DOTA-NOC uptake in the pancreas: pathological and physiological patterns. Clin. Nucl. Med. 37(1), 57-62 (2012).

Reubi JC, Waser B. Concomitant expression of several peptide receptors in neuroendocrine tumours: molecular basis for in vivo multireceptor tumour targeting. Eur. J. Nucl. Med. Mol. Imaging 30(5), 781-793 (2003).

52 Koukouraki S, Strauss LG, Georgoulias V et al. Evaluation of the pharmacokinetics of ${ }^{68} \mathrm{Ga}$-DOTATOC in patients with metastatic neuroendocrine tumours scheduled for ${ }^{90}$ Y-DOTATOC therapy. Eur. J. Nucl. Med. Mol. Imaging 33(4), 460-466 (2006).

$\checkmark 53$ Putzer D, Gabriel M, Henninger B et al. Bone metastases in patients with neuroendocrine tumor: ${ }^{68} \mathrm{Ga}$-DOTA-Tyr3-octreotide PET in comparison to CT and bone scintigraphy. J. Nucl. Med. 50 (8), 1214-1221 (2009).

54 Versari A, Camellini L, Carlinfante G et al. Ga-68 DOTATOC PET, endoscopic ultrasonography, and multidetector CT in the diagnosis of duodenopancreatic neuroendocrine tumors: a single-centre retrospective study. Clin. Nucl. Med. 35(5), 321-328 (2010)

55 Stats calculator. http://ktclearinghouse.ca/ $\mathrm{cebm} / \mathrm{practise} / \mathrm{ca} / \mathrm{calculators} / \mathrm{statscalc}$

${ }_{56}$ Kayani I, Bomanji JB, Groves A et al. Functional imaging of neuroendocrine tumors with combined PET/CT using ${ }^{68} \mathrm{Ga}$-DOTATATE (DOTA-DPhe1, Tyr3-octreotate) and ${ }^{18} \mathrm{~F}$-FDG. Cancer 112(11), 2447-2455 (2008).

57 Kayani I, Conry BG, Groves AM et al. A comparison of ${ }^{68} \mathrm{Ga}$-DOTATATE and ${ }^{18} \mathrm{~F}$-FDG PET/CT in pulmonary neuroendocrine tumors. J. Nucl. Med. 50(12), 1927-1932 (2009).

\$5 Haug A, Auernhammer CJ, Wängler B et al. Intraindividual comparison of ${ }^{68} \mathrm{Ga}$-DOTATATE and ${ }^{18} \mathrm{~F}$-DOPA PET in patients with well-differentiated metastatic neuroendocrine tumours. Eur. J. Nucl. Med. Mol. Imaging 36(5), 765-770 (2009).

59 Kabasakal L, Demirci E, Ocak M et al. Comparison of ${ }^{68} \mathrm{Ga}$-DOTATATE and ${ }^{68} \mathrm{Ga}$-DOTANOC PET/CT imaging in the same patient group with neuroendocrine tumours. Eur. J. Nucl. Med. Mol. Imaging 39(8), 1271-1277 (2012).

- One of the few head-to-head studies comparing two PET somatostatin receptor tracers in the same patients.

60 Wild D, Bomanji JB, Benkert P et al. Comparison of ${ }^{68} \mathrm{Ga}$-DOTANOC and ${ }^{68} \mathrm{Ga}$-DOTATATE PET/CT within patients with gastroenteropancreatic neuroendocrine tumors. J. Nucl. Med. 54(3), 364-372 (2013).

-• One of the few head-to-head studies comparing two PET somatostatin receptor tracers in the same patients.

Ambrosini V, Tomassetti P, Castellucci P et al. Comparison between ${ }^{68} \mathrm{Ga}$-DOTA- 
NOC and ${ }^{18} \mathrm{~F}-\mathrm{DOPA}$ PET for the detection of gastro-entero-pancreatic and lung neuro-endocrine tumours. Eur. J. Nucl. Med. Mol. Imaging 35(8), 1431-1438 (2008).

62 Ambrosini V, Castellucci P, Rubello D et al. ${ }^{68}$ Ga-DOTA-NOC: a new PET tracer for evaluating patients with bronchial carcinoid. Nucl. Med. Commun. 30(4), 281-286 (2009).

63 Ambrosini V, Nanni C, Zompatori M et al. ${ }^{68} \mathrm{Ga}$-DOTA-NOC PET/CT in comparison with CT for the detection of bone metastasis in patients with neuroendocrine tumours. Eur. J. Nucl. Med. Mol. Imaging 37(4), 722-727 (2010).

- 64 Naswa N, Sharma P, Kumar A et al. Gallium-68-DOTA-NOC PET/CT of patients with gastroenteropancreatic neuroendocrine tumors: a prospective single-center study. Am. J. Roentgenol. 197(5), 1221-1228 (2011).

65 Naswa N, Sharma P, Soundararajan R et al. Diagnostic performance of somatostatin receptor PET/CT using ${ }^{68} \mathrm{Ga}$-DOTANOC in gastrinoma patients with negative or equivocal CT findings. Abdom. Imaging 38(3), 552-560 (2013).

66 Ambrosini V, Campana D, Tomassetti P, Fanti S. ${ }^{68} \mathrm{Ga}$-labelled peptides for diagnosis of gastroenteropancreatic NET. Eur. J. Nucl. Med. Mol. Imaging 39(Suppl. 1), S52-S60 (2012).

67 Poeppel TD, Binse I, Petersenn S et al. ${ }^{68} \mathrm{Ga}$-DOTATOC versus ${ }^{68} \mathrm{Ga}$-DOTATATE $\mathrm{PET} / \mathrm{CT}$ in functional imaging of neuroendocrine tumors. J. Nucl. Med. 52(12), 1864-1870 (2011).

- One of the few head-to-head studies comparing two PET somatostatin receptor tracers in the same patients.

68 Putzer D, Kroiss A, Waitz D et al. Somatostatin receptor PET in neuroendocrine tumours: ${ }^{68} \mathrm{Ga}$-DOTA (0), Tyr (3)-octreotide versus ${ }^{68} \mathrm{Ga}$-DOTA (0)-lanreotide. Eur. J. Nucl. Med. Mol. Imaging 40 (3), 364-371. (2013).

-• One of the few head-to-head studies comparing two PET somatostatin receptor tracers in the same patients.

69 Demirci E, Ocak M, Kabasakal L, Araman A, Ozsoy Y, Kanmaz B. Comparison of Ga-68 DOTA-TATE and Ga-68 DOTA-LAN PET/ CT imaging in the same patient group with neuroendocrine tumours. Nucl. Med. Commun. 34(8), 727-732 (2013).

- One of the few head-to-head studies comparing two PET somatostatin receptor tracers in the same patients.
Treglia G, Castaldi P, Rindi G, Giordano A, Rufini V. Diagnostic performance of gallium-68 somatostatin receptor PET and $\mathrm{PET} / \mathrm{CT}$ in patients with thoracic and gastroenteropancreatic neuroendocrine tumours: a meta-analysis. Endocrine 42(1), 80-87 (2012).

-• Excellent meta-analysis of ${ }^{68} \mathrm{Ga}$-based somatostatin receptor PET tracers.

71 Jindal T, Kumar A, Venkitaraman B, Dutta R, Kumar R. Role of ${ }^{68} \mathrm{Ga}$-DOTATOC PET/ $\mathrm{CT}$ in the evaluation of primary pulmonary carcinoids. Korean J. Intern. Med. 25(4), 386-391 (2010).

72 Panzuto F, Nasoni S, Falconi M et al. Prognostic factors and survival in endocrine tumor patients: comparison between gastrointestinal and pancreatic localization. Endocr. Relat. Cancer 12(4), 1083-1092 (2005).

73 Gupta S, Johnson MM, Murthy R et al. Hepatic arterial embolization and chemoembolization for the treatment of patients with metastatic neuroendocrine tumors: variables affecting response rates and survival. Cancer 104(8), 1590-1602 (2005).

74 Prasad V, Ambrosini V, Hommann M, Hoersch D, Fanti S, Baum RP. Detection of unknown primary neuroendocrine tumours (CUP-NET) using ${ }^{68} \mathrm{Ga}$-DOTA-NOC receptor PET/CT. Eur. J. Nucl. Med. Mol. Imaging 37(1), 67-77 (2010).

\section{Naswa N, Sharma P, Kumar A et al.} ${ }^{68} \mathrm{Ga}$-DOTANOC PET/CT in patients with carcinoma of unknown primary of neuroendocrine origin. Clin. Nucl. Med. 37(3), 245-251 (2012).

-76 Łapińska G, Bryszewska M, FijołekWarszewska A, Kozłowicz-Gudzińska I, Ochman P, Sackiewicz-Słaby A. The diagnostic role of ${ }^{68} \mathrm{Ga}$-DOTATATE PET/CT in the detection of neuroendocrine tumours. Nucl. Med. Rev. Cent. East Eur. 14(1), 16-20 (2011).

77 Fanti S, Ambrosini V, Tomassetti P et al. Evaluation of unusual neuroendocrine tumours by means of ${ }^{68} \mathrm{Ga}$-DOTA-NOC PET. Biomed. Pharmacother. 62(10), 667-671 (2008).

Frilling A, Sotiropoulos GC, Radtke A et al. The impact of ${ }^{68} \mathrm{Ga}$-DOTATOC positron emission tomography/computed tomography on the multimodal management of patients with neuroendocrine tumors. Ann. Surg. 252(5), 850-856 (2010).

79 Froeling V, Elgeti F, Maurer MH et al. Impact of Ga-68 DOTATOC PET/CT on the diagnosis and treatment of patients with multiple endocrine neoplasia. Ann. Nucl. Med. 26(9), 738-743 (2012).

80 Ambrosini V, Campana D, Bodei L et al. ${ }^{68} \mathrm{Ga}$-DOTANOC PET/CT clinical impact in patients with neuroendocrine tumors. J. Nucl. Med. 51(5), 669-673 (2010).

-81 Pettinato C, Sarnelli A, Di Donna M et al. ${ }^{68} \mathrm{Ga}$-DOTANOC: biodistribution and dosimetry in patients affected by neuroendocrine tumors. Eur. J. Nucl. Med. Mol. Imaging 35(1), 72-79 (2008).

82 Hartmann H, Zöphel K, Freudenberg R et al. [Radiation exposure of patients during ${ }^{68} \mathrm{Ga}$-DOTATOC PET/CT examinations]. Nuklearmedizin 48(5), 201-207 (2009).

83 Walker RC, Smith GT, Liu E, Moore B, Clanton J, Stabin M. Measured human dosimetry of ${ }^{68}$ Ga-DOTATATE. J. Nucl. Med. 54(6), 855-860. (2013).

84 Castellucci P, Pou Ucha J, Fuccio C et al. Incidence of increased ${ }^{68} \mathrm{Ga}$-DOTANOC uptake in the pancreatic head in a large series of extrapancreatic NET patients studied with sequential PET/CT. J. Nucl. Med. 52(6), 886-890 (2011).

85 Luboldt W, Hartmann H, Wiedemann B, Zöphel K, Luboldt H-J.

Gastroenteropancreatic neuroendocrine tumors: standardizing therapy monitoring with ${ }^{68} \mathrm{Ga}$-DOTATOC PET/CT using the example of somatostatin receptor radionuclide therapy. Mol. Imaging 9(6), 351-358 (2010).

86 Kwekkeboom DJ, Kooi J. PP, Bakker WH, Mäcke HR, Krenning EP. Comparison of ${ }^{111}$ In-DOTA-Tyr3-octreotide and ${ }^{111}$ In-DTPAoctreotide in the same patients: biodistribution, kinetics, organ and tumor uptake. J. Nucl. Med. 40(5), 762-767 (1999).

87 Ruf J, Schiefer J, Furth C et al. ${ }^{68} \mathrm{Ga}-$ DOTATOC PET/CT of neuroendocrine tumors: spotlight on the CT phases of a triple-phase protocol. J. Nucl. Med. 52(5), 697-704 (2011).

-88 Mayerhoefer ME, Schuetz M, Magnaldi S, Weber M, Trattnig S, Karanikas G. Are contrast media required for ${ }^{68} \mathrm{Ga}$-DOTATOC $\mathrm{PET} / \mathrm{CT}$ in patients with neuroendocrine tumours of the abdomen? Eur. Radiol. 22(4), 938-946 (2012).

89 Schreiter NF, Nogami M, Steffen I et al. Evaluation of the potential of PET-MRI fusion for detection of liver metastases in patients with neuroendocrine tumours. Eur. Radiol. 22(2), 458-467 (2012).

-90 Giesel FL, Kratochwil C, Mehndiratta A et al. Comparison of neuroendocrine tumor detection and characterization using DOTATOC-PET in correlation with contrast 
enhanced CT and delayed contrast enhanced MRI. Eur. J. Radiol. 81(10), 2820-2825 (2012).

-91 Gaertner FC, Beer AJ, Souvatzoglou M et al. Evaluation of feasibility and image quality of ${ }^{68} \mathrm{Ga}$-DOTATOC positron emission tomography/magnetic resonance in comparison with positron emission tomography/computed tomography in patients with neuroendocrine tumors. Invest. Radiol. 48(5), 263-272 (2013).

92 Kjær A, Loft A, Law I et al. PET/MRI in cancer patients: first experiences and vision from Copenhagen. MAGMA 26(1), 37-47 (2013).

93 Beiderwellen KJ, Poeppel TD, HartungKnemeyer $\mathrm{V}$ et al. Simultaneous ${ }^{68} \mathrm{Ga}-$ DOTATOC PET/MRI in patients with gastroenteropancreatic neuroendocrine tumors: initial results. Invest. Radiol. 48(5), 273-279 (2013).

$\$ 4$ Putzer D, Gabriel M, Kendler D et al. Comparison of ${ }^{68} \mathrm{Ga}$-DOTA-Tyr(3)- octreotide and ${ }^{18} \mathrm{~F}$-fluoro-Ldihydroxyphenylalanine positron emission tomography in neuroendocrine tumor patients. Q. J. Nucl. Med. Mol. Imaging 54(1), 68-75 (2010).

-95 Binderup T, Knigge U, Loft A, Federspiel B, Kjær A. ${ }^{18} \mathrm{~F}$-fluorodeoxyglucose positron emission tomography predicts survival of patients with neuroendocrine tumors. Clin. Cancer Res. 16(3), 978-985 (2010).

$\$ 96$ Binderup T, Knigge U, Loft A et al. Functional imaging of neuroendocrine tumors: a head-to-head comparison of somatostatin receptor scintigraphy, ${ }^{123}$ I-MIBG scintigraphy, and ${ }^{18} \mathrm{~F}-\mathrm{FDG}$ PET. J. Nucl. Med. 51(5), 704-712 (2010).

- 97 Oh S, Prasad V, Lee DS, Baum RP. Effect of peptide receptor radionuclide therapy on somatostatin receptor status and glucose metabolism in neuroendocrine tumors: intraindividual comparison of Ga-68 DOTANOC PET/CT and F-18 FDG PET/ CT. Int J. Mol. Imaging 2011, 524130 (2011).
-98 Wild D, Mäcke H, Christ E, Gloor B, Reubi JC. Glucagon-like peptide 1-receptor scans to localize occult insulinomas. $N$. Engl. J. Med. 359(7), 766-768 (2008).

99 Christ E, Wild D, Forrer F et al. Glucagonlike peptide-1 receptor imaging for localization of insulinomas. J. Clin. Endocrinol. Metab. 94(11), 4398-4405 (2009).

100 Eriksson O, Velikyan I, Selvaraju RK et al. Detection of metastatic insulinoma by positron emission tomography with $[(68) \mathrm{Ga}]$ exendin-4 - a case report. J. Clin. Endocrinol. Metab. 99(5), 1519-1524 (2014).

101 Wild D, Theodoraki A, Kurzawinski TR et al. 'Running on empty'. Eur. J. Nucl. Med. Mol. Imaging 37(7), 1439-1440 (2010).

102 Wild D, Christ E, Caplin ME et al. Glucagon-like peptide-1 versus somatostatin receptor targeting reveals 2 distinct forms of malignant insulinomas. J. Nucl. Med. 52(7), 1073-1078 (2011). 